\title{
ApoSOD1 lacking dismutase activity neuroprotects motor neurons exposed to beta-methylamino-L-alanine through the $\mathrm{Ca}^{2+} / \mathrm{Akt} / \mathrm{ERK} 1 / 2$ prosurvival pathway
}

\author{
Tiziana Petrozziello ${ }^{1}$, Agnese Secondo ${ }^{*, 1}$, Valentina Tedeschi ${ }^{1}$, Alba Esposito ${ }^{1}$, MariaJosè Sisalli ${ }^{1}$, Antonella Scorziello ${ }^{1}$, \\ Gianfranco Di Renzo ${ }^{1}$ and Lucio Annunziato ${ }^{\star, 1,2}$
}

Amyotrophic lateral sclerosis (ALS) is a severe human adult-onset neurodegenerative disease affecting lower and upper motor neurons. In $>20 \%$ of cases, the familial form of ALS is caused by mutations in the gene encoding $\mathrm{Cu}, \mathrm{Zn}$-superoxide dismutase (SOD1). Interestingly, administration of wild-type SOD1 to SOD1 ${ }^{\mathrm{G93A}}$ transgenic rats ameliorates motor symptoms through an unknown mechanism. Here we investigated whether the neuroprotective effects of SOD1 are due to the $\mathrm{Ca}^{2+}$-dependent activation of such prosurvival signaling pathway and not to its catalytic activity. To this aim, we also examined the mechanism of neuroprotective action of ApoSOD1, the metal-depleted state of SOD1 that lacks dismutase activity, in differentiated motor neuron-like NSC-34 cells and in primary motor neurons exposed to the cycad neurotoxin beta-methylamino-L-alanine (L-BMAA). Preincubation of ApoSOD1 and SOD1, but not of human recombinant SOD1 ${ }^{\text {G93A }}$, prevented cell death in motor neurons exposed to L-BMAA. Moreover, ApoSOD1 elicited ERK1/2 and Akt phosphorylation in motor neurons through an early increase of intracellular $\mathrm{Ca}^{2+}$ concentration $\left(\left[\mathrm{Ca}^{2+}\right]\right.$ i). Accordingly, inhibition of ERK1/2 by siMEK1 and PD98059 counteracted ApoSOD1- and SOD1-induced neuroprotection. Similarly, transfection of the dominant-negative form of Akt in NSC-34 motor neurons and treatment with the selective PI3K inhibitor LY294002 prevented ApoSOD1and SOD1-mediated neuroprotective effects in L-BMAA-treated motor neurons. Furthermore, ApoSOD1 and SOD1 prevented the expression of the two markers of L-BMAA-induced ER stress GRP78 and caspase-12. Collectively, our data indicate that ApoSOD1, which is devoid of any catalytic dismutase activity, exerts a neuroprotective effect through an early activation of $\mathrm{Ca}^{2+} / \mathrm{Akt} / \mathrm{ERK} 1 / 2 \mathrm{pro}-$ survival pathway that, in turn, prevents ER stress in a neurotoxic model of ALS.

Cell Death and Differentiation (2017) 24, 511-522; doi:10.1038/cdd.2016.154; published online 13 January 2017

Amyotrophic lateral sclerosis (ALS) is a human adult-onset neurodegenerative disease characterized by the loss of upper motor neurons in the cerebral cortex and lower motor neurons in the brainstem and spinal cord. ${ }^{1,2}$ In about $20 \%$ of cases, familial ALS is associated with mutations in the gene encoding $\mathrm{Cu}, \mathrm{Zn}$-superoxide dismutase (SOD1). However, mutations in SOD1 are also associated with some sporadic cases of the disease. $^{3,4}$ The pathogenesis of ALS is yet unknown. However, many data suggest that mutations in SOD1 cause motor neuron degeneration probably through a gain of toxic function rather than a loss of function. Indeed, most of the mutated SOD1s preserve their catalytic activity and accumulate in the cytoplasm causing motor neuron degeneration. In particular, in ALS, because SOD1 secretion is compromised, aggregates of mutated SOD1 accumulate in the endoplasmic reticulum (ER) and Golgi apparatus, ${ }^{5}$ thus causing motor neuron degeneration, ${ }^{6}$ mitochondrial dysfunction, ${ }^{7}$ and ER stress. ${ }^{8}$ Recently, Proctor et $a l^{9}{ }^{9}$ demonstrated that these aggregates causing motor neuronal death are trimers of nonnative unfolded species of different types of SOD1. Furthermore, these authors showed that wild-type enzyme, once transfected in NSC-34 cells, did not induce per se SOD1 trimer formation, thus suggesting that the enzyme remains structurally stable under controlled conditions. Indeed the stability of SOD1 is affected by disease-related mutations and by several posttransductional modifications inducing dissociation of the enzyme toward trimer formation. ${ }^{10,11}$ On the other hand, it has been shown that intrathecal treatment with hSOD ${ }^{\text {wt }}$ delays disease progression and prolongs survival in SOD1 ${ }^{\text {G93A }}$ rats. ${ }^{6}$ However, the molecular mechanism by which SOD1 exerts these effects in ALS is still unknown.

Moreover, it has been hypothesized that mutations in metalfree apoprotein ApoSOD1, which lacks catalytic activity may have a more important role in ALS pathogenesis than alterations in holoprotein structure. ${ }^{12}$ Indeed, SOD1 ${ }^{\mathrm{A} 4 \mathrm{~V}}$ and SOD1 ${ }^{\mathrm{C} 6 \mathrm{~F}}$ mutations, which affect both holoprotein and apoprotein structures, are associated with an early onset of the pathology and with a 2-year reduction in life expectancy after diagnosis. ${ }^{13}$ Instead, SOD ${ }^{\mathrm{D} 90 \mathrm{~A}}$ mutation, which only marginally affects the apoprotein sequence, determines a survival time of almost 14 years. ${ }^{14}$

SOD1 belongs to a family of metal proteins that catalyze the dismutation of superoxide anion $\left(\mathrm{O}_{2}^{-}\right)$in molecular oxygen $\left(\mathrm{O}_{2}\right)$ and hydrogen peroxide $\left(\mathrm{H}_{2} \mathrm{O}_{2}\right) \cdot{ }^{15}$ In both neuronal and non-neuronal cells, SOD1 is secreted via an ATP-dependent process that requires the activation of the SNARE complex. ${ }^{16}$

\footnotetext{
'Division of Pharmacology, Department of Neuroscience, Reproductive and Odontostomatological Sciences, School of Medicine, "Federico II" University of Naples, Via Sergio Pansini 5, Naples, Italy and ${ }^{2}$ Fondazione IRCCS SDN, Naples, Italy

*Corresponding author: L Annunziato or A Secondo, Division of Pharmacology, Department of Neuroscience, Reproductive and Odontostomatological Sciences, School of Medicine, "Federico II" University of Naples, Via Sergio Pansini 5, Naples 80131, Italy. Tel: +390817463325 or +39 0817462103; Fax: +390817463323; E-mail: lannunzi@unina.it or secondo@unina.it

Received 12.7.16; revised 04.11.16; accepted 24.11.16; Edited by N Bazan; published online 13.1.2017
} 
However, when exogenously administered in neuroblastoma cells, SOD1 - as well as the metal-depleted state ApoSOD1 rapidly activates the $\mathrm{PLC} / \mathrm{PKC} / \mathrm{Ca}^{2+}$ pathway independently from its dismutase activity. ${ }^{17}$

We thus investigated whether ApoSOD1, which is devoid of any dismutase catalytic activity, exerts a neuroprotective effect on dysfunctional motor neurons by activating the $\mathrm{Ca}^{2+}$ -dependent Akt/ERK1/2 pathway. To this aim, motor neurons were exposed to the cycad toxin beta-methylamino-L-alanine (L-BMAA), which causes the Guam form of ALS.

\section{Results}

SOD1 neuroprotected NSC-34 motor neurons exposed to the cycad toxin L-BMAA through a $\mathrm{Ca}^{2+}$-dependent activation of $A k t / E R K 1 / 2$ prosurvival pathway. L-BMAA, a neurotoxic non-protein amino acid produced by cyanobacteria, is associated with amyotrophic lateral sclerosisParkinson dementia complex (ALS-PDC), a neurological disease affecting an indigenous population in Guam. ${ }^{18}$

NSC-34 motor neurons, a mouse-mouse hybrid cell line between neuroblastoma cells and spinal cord, were differentiated with $10 \mu \mathrm{M}$ retinoic acid for $48 \mathrm{~h}$ (Figure 1a). Under these conditions, differentiated NSC-34 cells displayed a multipolar neuron-like phenotype expressing the motor neuronal neurofilament $\mathrm{H}, \mathrm{SMI}-32$ (Figure 1a), and released SOD1 in the extracellular medium after depolarization with $55 \mathrm{mM} \mathrm{K}^{+}$ (Figure 1b). This effect was prevented by EGTA (Figure 1b).

To verify the effect of SOD1 on L-BMAA-induced cell death, motor neurons were preincubated with different concentrations of SOD1 $(40-4000 \mathrm{ng} / \mathrm{ml})$ for $10 \mathrm{~min}$ and then incubated with L-BMAA (300 $\mu \mathrm{M}$ for $48 \mathrm{~h}$ ), a condition that reduced cell viability of about $50 \%$ (Figure 1c). Under these conditions, SOD1 prevented L-BMAA-induced cell death in a dosedependent manner (Figure 1c) with an $E_{50}$ of $400 \mathrm{ng} / \mathrm{ml}$. Moreover, at this concentration, SOD1 reduced reactive oxygen species (ROS) levels induced by the neurotoxin, as detected by $2^{\prime}, 7^{\prime}$-dichlorfluorescein-diacetate (DCFH-DA) fluorescent dye (Figure 1d).

To study the signal transduction mechanisms elicited by SOD1 in motor neurons, we first analyzed the effect of SOD1 on $\left[\mathrm{Ca}^{2+}\right]_{i}$. SOD1 exposure $(400 \mathrm{ng} / \mathrm{ml})$ induced a rapid increase of $\left[\mathrm{Ca}^{2+}\right]_{i}$ in differentiated NSC-34 cells (Figure 2a). This effect was partially reduced in a $\mathrm{Ca}^{2+}$-free solution (Figure 2b). Indeed, SOD1-induced $\left[\mathrm{Ca}^{2+}\right]_{\mathrm{i}}$ increase was totally prevented when the enzyme was administered in $\mathrm{Ca}^{2+}$-free solution to NSC-34 motor neurons previously preincubated with thapsigargin $(1 \mu \mathrm{M})$, a specific sarco/ endoplasmic reticulum calcium ATPasi inhibitor able to deplete $\mathrm{Ca}^{2+}$ from ER (Figure $2 \mathrm{~b}$ ). Then we verified the ability of SOD1 to induce the activation of some $\mathrm{Ca}^{2+}$ dependent mechanisms, including ERK1/2 and Akt in NSC-34 motor neurons. After a 10 min incubation with SOD1 (400 ng/ $\mathrm{ml}), \mathrm{ERK} 1 / 2$ and Akt phosphorylation was significantly increased compared with controls (Figures 2c and d). Furthermore, the dominant-negative form of Akt (Akt D-) encoding for an inactive kinase counteracted SOD1-induced phosphorylation of GSK3 $\beta$, a downstream target of Akt (Figure 3a). Moreover, the silencing of MEK
(siMEK) prevented SOD1-induced phosphorylation of ERK1/2 (Figure 3b). Interestingly, transient transfection of Akt $D$ - prevented also the phosphorylation of ERK1/2 induced by SOD1 (Figure 3c). Furthermore, siMEK1 and the inhibitor of ERK1/2 PD98059 $(50 \mu \mathrm{M})$ as well as Akt D- and the PI3K inhibitor LY294002 (10 $\mu \mathrm{M})$ counteracted the neuroprotection induced by SOD1 in motor neurons exposed to L-BMAA $(300 \mu \mathrm{M} / 48 \mathrm{~h})$ (Figures 3d and e).

ApoSOD1, which lacks dismutase catalytic activity, neuroprotected NSC-34 motor neurons exposed to L-BMAA through the $\mathrm{Ca}^{2+}$-dependent activation of Akt/ ERK1/2 prosurvival pathway and prevented ER stress. As we hypothesized that the SOD1-mediated neuroprotective effect in L-BMAA-treated cells could be ascribed to Akt and ERK1/2 activation, we examined the effect of ApoSOD1 in the same experimental paradigm. Furthermore, we compared the effects of SOD1 and ApoSOD1 on the structurally unrelated SOD mimetic MnTMPyP pentachloride, which has the same catalytic activity as SOD1. To inactivate SOD1, the protein was exposed to $\mathrm{H}_{2} \mathrm{O}_{2}(200 \mathrm{mM})$ at different time points; then to stop the reaction, it was exposed to catalase $(1000 \mathrm{U} / \mathrm{ml})$. Under these conditions, ApoSOD1 presented the same molecular weight as SOD1 (Figure 4a, top). Furthermore, as described in the Materials and Methods section, ApoSOD1 activity was measured indirectly by a colorimetric assay. We observed a timedependent decrease in ApoSOD1 activity, reaching peak inactivation $60 \mathrm{~min}$ after treatment (Figure 4a). Next we compared the catalytic activity of ApoSOD1 with that of SOD1 in a more direct assay by measuring the ability of these proteins to reduce ROS production in hypoxic motor neurons. Under these conditions, ApoSOD1 $(400 \mathrm{ng} / \mathrm{ml})$ failed to reduce $\mathrm{ROS}$ production, whereas SOD1 significantly reduced DCF-DA-monitored fluorescence associated with the increase of ROS levels in NSC-34 cells exposed to $45 \mathrm{~min}$ of chemical hypoxia (Figure $4 \mathrm{~b}$ ). Then, to verify the transductional effect of ApoSOD1 in motor neurons, we analyzed the effect of this protein on $\left[\mathrm{Ca}^{2+}\right]_{\mathrm{i}}$. ApoSOD1 $(400 \mathrm{ng} / \mathrm{ml})$ exposure induced a rapid increase in $\left[\mathrm{Ca}^{2+}\right]_{i}$ in differentiated NSC-34 cells (Figure 4c). However, this effect was partially reduced in a $\mathrm{Ca}^{2+}$-free solution (Figure 4d). Indeed, ApoSOD1-induced $\left[\mathrm{Ca}^{2+}\right]_{\mathrm{i}}$ increase was totally prevented when the metal-free apoenzyme was added to a $\mathrm{Ca}^{2+}$-free solution in NSC-34 motor neurons previously preincubated with thapsigargin (Figure 4d). Afterward, we verified whether ApoSOD1 was able to activate some of the $\mathrm{Ca}^{2+}$-dependent mechanisms, including ERK1/2 and Akt, in NSC-34 motor neurons. After $10 \mathrm{~min}$ of incubation with ApoSOD1 (400 ng/ml), ERK1/2 and Akt phosphorylation significantly increased compared with controls (Figures $4 \mathrm{e}$ and f).

We thus compared the potential neuroprotective effects exerted by ApoSOD1 and the structurally unrelated MnTMPyP pentachloride in NSC-34 motor neurons exposed to L-BMAA $(300 \mu \mathrm{M} / 48 \mathrm{~h})$. We found that, similar to SOD1, ApoSOD1 prevented L-BMAA-induced cell death in NSC-34 motor neurons, whereas MnTMPyP pentachloride failed to do so (Figure 5a). Moreover, ApoSOD1 neuroprotective effect was 
a
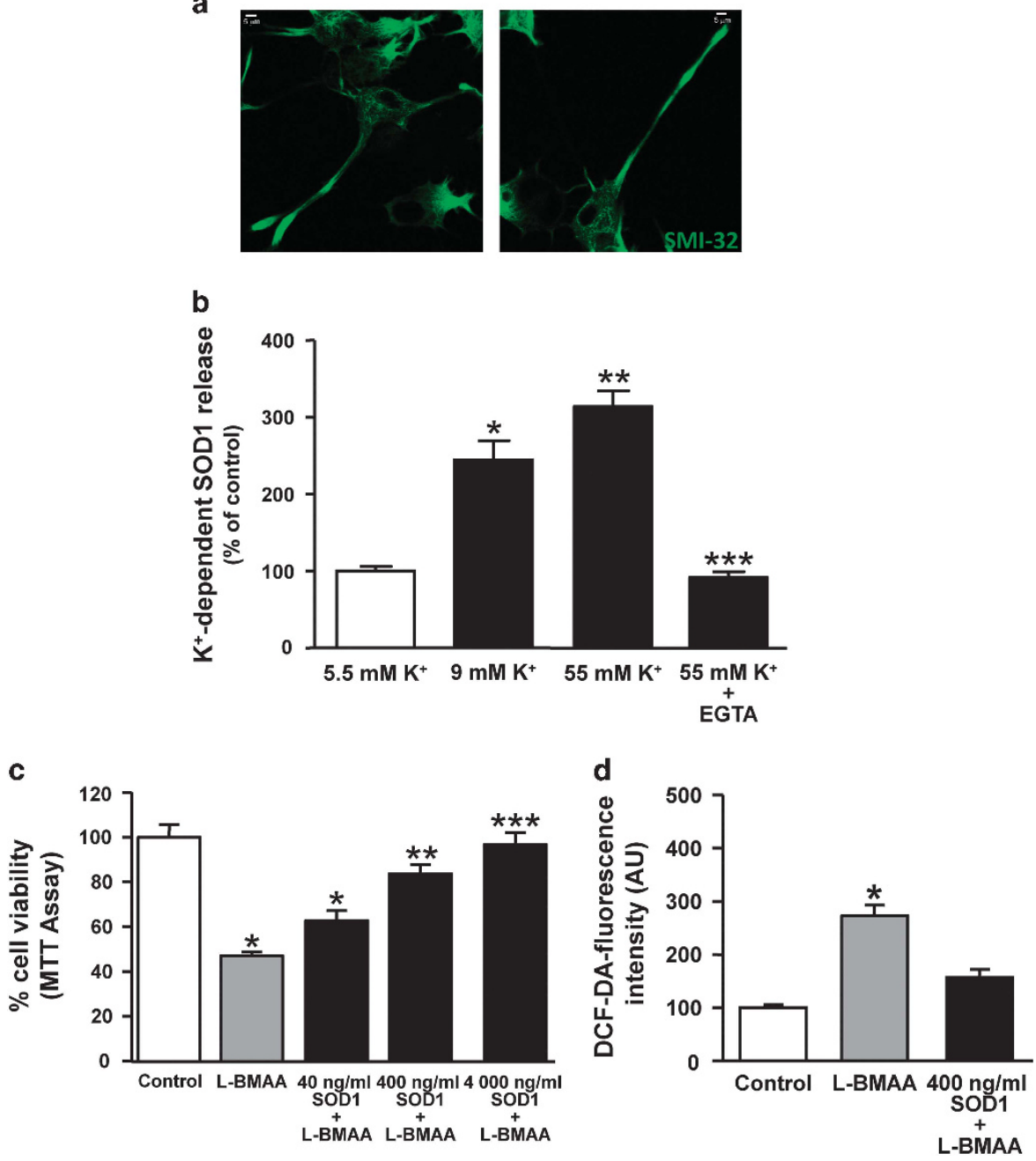

Figure 1 Effects of SOD1 on L-BMAA-induced cell death in NSC-34 motor neurons. (a) Immunocytochemical images of SMI-32 in differentiated NSC-34 motor neurons. (b) Bar graph depicting the effect of high $\mathrm{K}^{+}$solution $(55 \mathrm{mM})$ on SOD1 release from differentiated NSC-34 motor neurons. Data are expressed as mean \pm S.E. of four different experiments. ${ }^{*} P<0.05$ versus Control; ${ }^{* *} P<0.05$ versus control and $9 \mathrm{mM} \mathrm{K+;}$; ${ }^{* \star} P<0.05$ versus $55 \mathrm{mM} \mathrm{K}^{+}$. (c) Bar graph depicting the effect of L-BMAA (300 $\mu \mathrm{M} / 48 \mathrm{~h}$ ) on cell survival of NSC-34 motor neurons pretreated $(10 \mathrm{~min})$ with 40,400 or $4000 \mathrm{ng} / \mathrm{ml} \mathrm{SOD1}$ and measured by MTT. Data are expressed as mean \pm S.E. of three different experimental sessions. ${ }^{*} P<0.05$ versus control; ${ }^{* *} P<0.05$ versus L-BMAA alone and $40 \mathrm{ng} / \mathrm{ml} \mathrm{SOD1} 1{ }^{* * *} P<0.05$ versus 40 and $400 \mathrm{ng} / \mathrm{ml}$ SOD1. (d) Bar graph depicting DCFDA-detected ROS production in NSC-34 motor neurons exposed to L-BMAA $(300 \mu \mathrm{M} / 48 \mathrm{~h})$ or L-BMAA plus SOD1 (400 ng/ml). Data are expressed as mean \pm S.E. of three different experiments. ${ }^{*} P<0.05$ versus control and $400 \mathrm{ng} / \mathrm{ml}$ SOD1+L-BMAA

counteracted by PD98059 and LY294002, two well-known inhibitors of ERK $1 / 2$ and Akt, respectively (Figure $5 \mathrm{~b}$ ).

Recent evidence shows that ER stress, usually involved in neurodegenerative diseases, has a key role in motor neuron degeneration in ALS. ${ }^{8}$ Accordingly, western blotting analysis showed that, after a $48 \mathrm{~h}$ exposure, L-BMAA induced an increase in GRP78 and caspase-12 expression levels in NSC-34 motor neurons. By contrast, preincubation with both SOD1 $(400 \mathrm{ng} / \mathrm{ml})$ and ApoSOD1 $(400 \mathrm{ng} / \mathrm{ml})$ prevented such increases in both $\mathrm{ER}$ stress markers (Figure $5 c$ and Figure 5d, respectively). Collectively, our results indicate that SOD1 protects motor neurons from ER stress-mediated neurodegeneration induced by L-BMAA independently of its dismutase activity.

SOD1 ${ }^{\text {G93A }}$ did not activate $\mathrm{Ca}^{2+} / \mathrm{Akt} / \mathrm{ERK} 1 / 2$ pathway and did not protect primary motor neurons exposed to L-BMAA. To compare the transductional effects of the better-characterized mutation in SOD1, the amino-acid substitution G93A, with that of the wild-type SOD1, we studied the effect of the recombinant wild-type SOD1 (rSOD1 ${ }^{\text {wt }}$ ) and the recombinant mutant SOD $1^{\mathrm{G} 93 \mathrm{~A}}$ (rSOD1 ${ }^{\mathrm{G} 93 \mathrm{~A}}$ ) on the $\mathrm{Ca}^{2+} / \mathrm{Akt} /$ ERK1/2 pathway in NSC-34 motor neurons. As already shown for extractive SOD1, rSOD $1^{\text {wt }}$ also induced ERK1/2 and Akt phosphorylation, whereas $\mathrm{rSOD} 1^{\mathrm{G} 93 \mathrm{~A}}$ failed to produce the same effects in NSC-34 motor neurons (Figures 6a and b). Furthermore rSOD1 ${ }^{\text {wt }}$ and SOD1, but not rSOD $1^{\mathrm{G} 93 \mathrm{~A}}$, prevented L-BMAA-induced neurotoxicity in differentiated NSC-34 motor neurons (Figure 6c).

Interestingly, in primary cultures of motor neurons expressing SMI-32 (Figure 7a), SOD1, ApoSOD1 and rSOD1 ${ }^{\text {wt }}$ induced a rapid increase in $\left[\mathrm{Ca}^{2+}\right]_{\mathrm{i}}$, whereas $\mathrm{rSOD}^{\mathrm{G} 93 \mathrm{~A}}$ did not (Figures 7b-f). Consistently, in the same cells, SOD1 and ApoSOD1 induced ERK1/2 and Akt phosphorylation (Figures $7 \mathrm{~g}$ and $\mathrm{h}$ ). Moreover, L-BMAA exposure determined a 

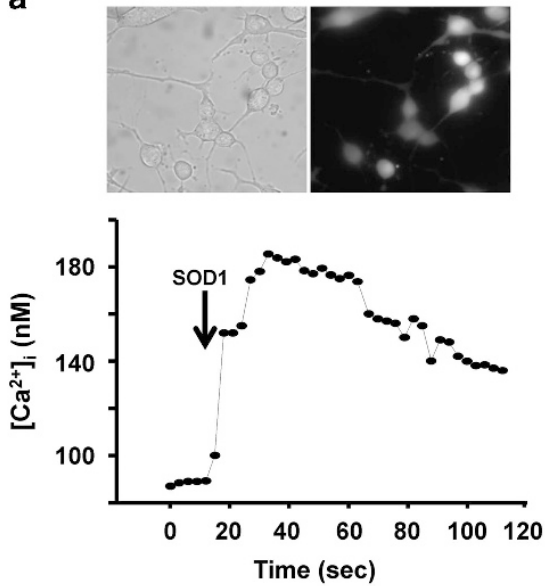

C
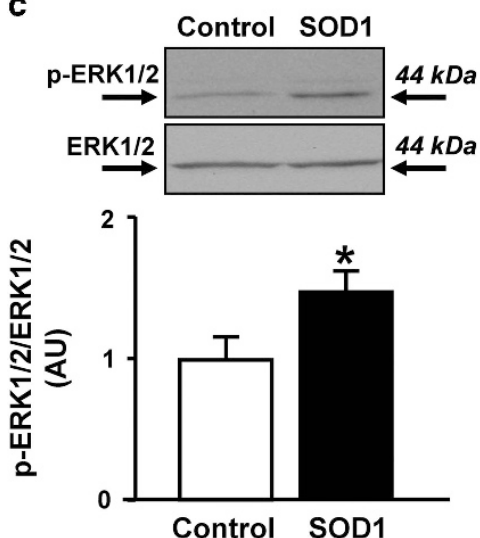

b
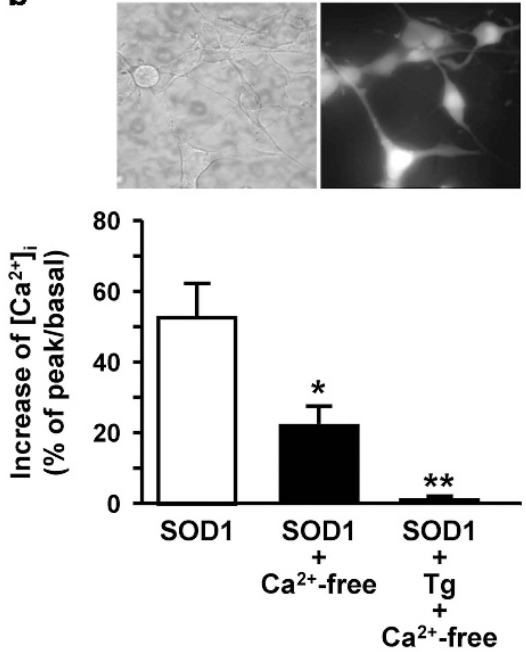

d
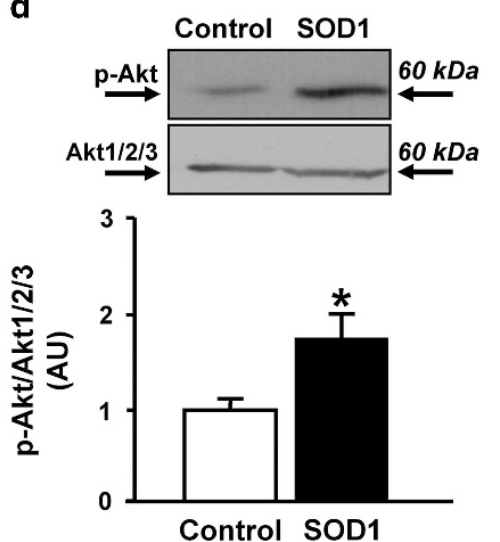

Figure 2 Effects of SOD1 on [Ca $\left.{ }^{2+}\right]_{i}$ and ERK1/2 and Akt phosphorylation in NSC-34 motor neurons. (a and $\mathbf{b}$ ) (Top) Representative images of NSC-34 motor neurons loaded with Fura-2/AM in control conditions. (Bottom a) Single-cell trace depicting $\left[\mathrm{Ca}^{2+}\right]_{\mathrm{i}}$ before and after SOD1 administration. (Bottom b) Quantification of the effect of SOD1, SOD1 in $\mathrm{Ca}^{2+}$-free and SOD1 in $\mathrm{Ca}^{2+}$-free + thapsigargin $(\mathrm{Tg})$ on $\left[\mathrm{Ca}^{2+}\right]$ SOD1 significantly increases $\left[\mathrm{Ca}^{2+}\right]$. Data are expressed as mean $\pm \mathrm{S}$. E. of three different experiments performed on $30 / 50$ cells. ${ }^{*} P<0.05$ versus SOD1. ${ }^{* *} P<0.05$ versus SOD1+ $\mathrm{Ca}^{2+}$-free. (c) Representative western blotting and quantification of the effect of SOD1 (400 $\mathrm{ng} / \mathrm{ml} / 10 \mathrm{~min}$ ) on p-ERK1/2 and ERK1/2 expression. (d) Representative western blotting and quantification of the effect of SOD1 (400 ng/m//10 min) on p-Akt and Akt1/2/3 expression. Data are expressed as mean \pm S.E. of three different experimental sessions. ${ }^{*} P<0.05$ versus respective control

time-dependent increase in cell death that was, however, prevented when the cells were preincubated with SOD1, ApoSOD1 and rSOD1 ${ }^{\text {wt }}$, but not with rSOD1 $^{\text {G93A }}$ (Figures $8 a$ and $b)$.

\section{Discussion}

This study has shown that the neuroprotective effect of SOD1 in motor neurons exposed to the cycad toxin L-BMAA, which causes the Guam form of ALS, is not dependent on its dismutase catalytic activity but rather on the activation of $\mathrm{Ca}^{2+} / \mathrm{Akt} / \mathrm{ERK} 1 / 2$ signaling pathway (see Figure $8 \mathrm{c}$ ) that, in turn, prevents ER stress. Furthermore, the exposure of motor neurons to ApoSOD1, the metal-free protein lacking catalytic activity, prevented both ER stress and cell death induced by the cycad toxin. This suggests that the neuroprotective effect of SOD1, which was released in a $\mathrm{Ca}^{2+}$-dependent manner, is exclusively dependent on the apo state of the protein and its ability to activate the prosurvival Akt/ERK1/2 signaling pathway. In particular, the phosphorylation of Akt and ERK1/2 induced by
ApoSOD1 and SOD1 was dependent on the elevation of $\left[\mathrm{Ca}^{2+}\right]_{\mathrm{i}}$, which partially flowed from the extracellular space and partially derived from ER. The activation of this pathway, in turn, prevented ER stress and reduced motor neuronal death in the neurotoxic model of the disease. Indeed, the dominant-negative form of Akt, Akt D - , and the PI3K inhibitor LY294002 prevented the ApoSOD1 protective effect on motor neurons exposed to L-BMAA. Similarly, silencing of the upstream kinase of ERK1/2, MEK1 or the pharmacological inhibition of ERK1/2 using PD98059 counteracted the neuroprotective effects exerted by ApoSOD1 in motor neurons exposed to L-BMAA.

ER stress resulting from the accumulation of misfolded proteins in the ER lumen and from an increase in the expression of several stress markers has been implicated in ALS. ${ }^{8}$ In accordance with this evidence, our data showed that in motor neurons the neuroprotective effect of SOD1 and ApoSOD1 via $\mathrm{Ca}^{2+} / \mathrm{Akt} / \mathrm{ERK} 1 / 2$ signaling pathway prevented the increase in two ER stress markers: GRP78, a molecular chaperon that activates the unfolded protein response, and 
a
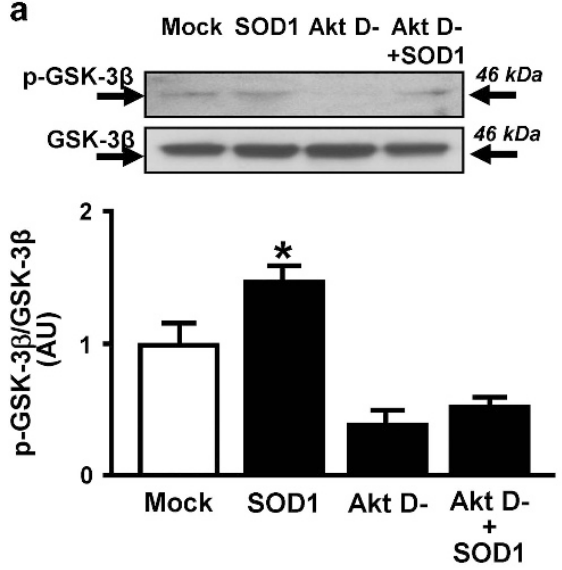

b
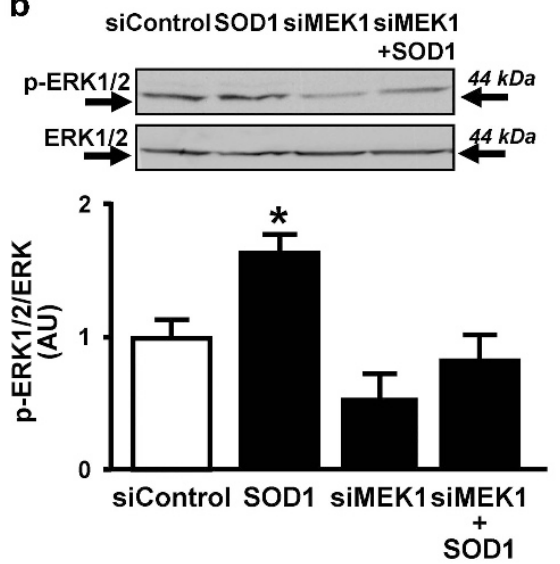
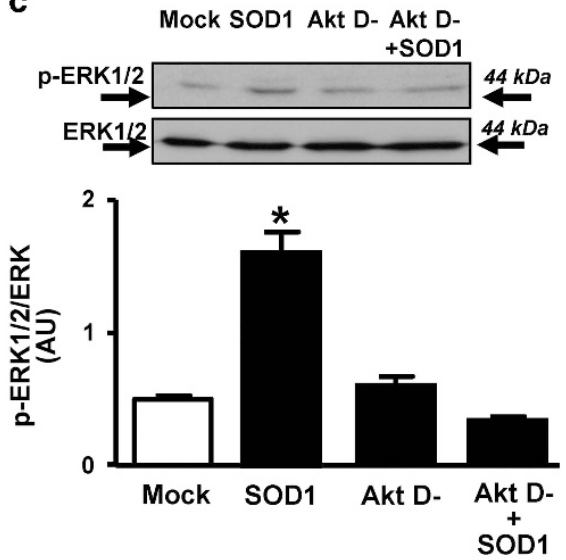

d

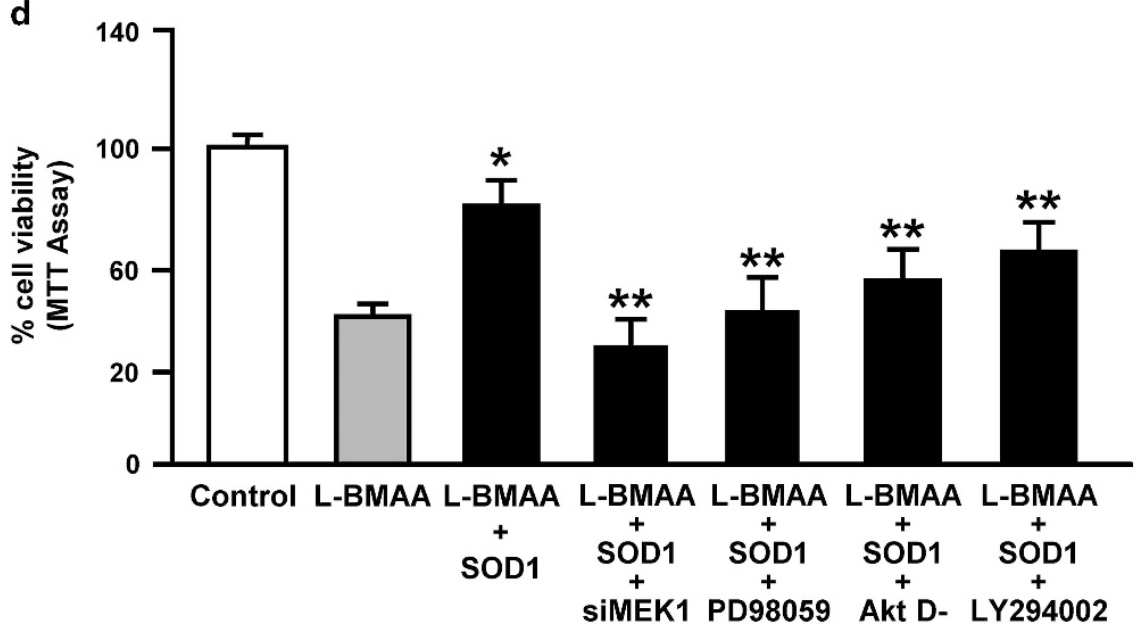

Figure 3 Effects of the inhibition of ERK1/2/Akt signaling pathway on SOD1-induced neuroprotection in NSC-34 motor neurons exposed to L-BMAA. (a) Western blotting and quantification of $\mathrm{p}$-GSK3 $\beta$ and GSK3 $\beta$ expression in NSC-34 cells transfected with Akt D - $(2 \mu \mathrm{g} / \mu \mathrm{l})$ and exposed to SOD1 (400 $\mathrm{ng} / \mathrm{ml} / 10 \mathrm{~min})$. NSC-34 cells were transfected with Akt D - or Mock $48 \mathrm{~h}$ before the exposure to SOD1. The transfection medium containing vectors was incubated for $5 \mathrm{~h}$ and then replaced with fresh medium. Data are expressed as mean \pm S.E. of three different experimental sessions. ${ }^{*} P<0.05$ versus the other experimental groups. (b) Western blotting and quantification of $p$-ERK1/2 and ERK1/2 expression in NSC-34 cells transfected with siMEK1 (10 nM) and exposed to SOD1 ( $400 \mathrm{ng} / \mathrm{ml} / 10 \mathrm{~min}$ ). NSC-34 cells were transfected with siMEK1 $48 \mathrm{~h}$ before the exposure to SOD1. The transfection medium containing duplexes was incubated for $5 \mathrm{~h}$ and then replaced with fresh medium. Data are expressed as mean \pm S.E. of three different experimental sessions. * $P<0.05$ versus the other experimental groups. (c) Western blotting and quantification of $p$-ERK1/2 and ERK1/2 expression in NSC-34 cells transfected with Akt D - or Mock $48 \mathrm{~h}$ before the exposure to SOD1. ${ }^{*} P<0.05$ versus the other experimental groups. (d) Bar graph depicting the effect of L-BMAA (300 $\mu \mathrm{M} / 48 \mathrm{~h}$ ) on cell death -measured by MTT - of NSC-34 motor neurons transfected with siMEK1 (10 nM) or treated with PD98059, or Akt D - $(2 \mu \mathrm{g} / \mu \mathrm{l})$ or treated with LY294002 and then exposed to SOD1 (400 ng/m/ $10 \mathrm{~min})$. Data are expressed as mean \pm S.E. of three different experimental sessions. L-BMAA was statistically different from control as shown in Figure 1c. ${ }^{*} P<0.05$ versus L-BMAA alone; ${ }^{* *} P<0.05$ versus L-BMAA+SOD1

caspases-12. These results demonstrate that, unlike the extracellular isoform SOD3, ${ }^{19}$ ApoSOD1 and SOD1 neuroprotection in motor neurons is independent of SOD1 antioxidant activity.

The first link between SOD1 and ALS was found in 1993 when autosomal-dominant mutations in sod1 gene were found in about $20 \%$ of the patients affected by the familial form of the disease. This evidence initially led to the hypothesis that ALS could result from the loss of function of the mutated enzymes. ${ }^{3}$ However, a year later, some authors discovered that most of the mutations of sod1 gene, including G93A, encoded enzymes that, instead, did maintain their catalytic activity. ${ }^{20}$ Consistently, it was shown that G93A transgenic mice developed progressive disease although SOD1 activity remained almost preserved. ${ }^{21}$ All of this evidence suggested that the catalytic activity of SOD1 could be irrelevant for the development of the disease. ${ }^{22}$ In line with these studies, we found that the recombinant form of SOD $1^{\text {G93A }}$ failed to induce Akt and ERK1/2 phosphorylation, to increase $\left[\mathrm{Ca}^{2+}\right]_{\mathrm{i}}$ and, therefore, to exert a neuroprotective effect on dysfunctional motor neurons. All these results reinforce the idea that SOD1 dismutase activity is not directly involved in the development of the motor neuronal disease and that the neuroprotection exerted by the enzyme is due to the transduction signaling pathway elicited by its wild-type form and not by G93A mutation. Furthermore, considering that SOD1 is normally secreted, as previously shown by other groups ${ }^{6,23,24}$ and by the results of the present study, we hypothesized that the defect in the release and, therefore, in the activation of the $\mathrm{Ca}^{2+} / \mathrm{Akt} / \mathrm{ERK} 1 / 2$ prosurvival pathway, might represent a degenerative event for motor neurons in the Chamorro-form of ALS. Accordingly, it has been shown that intrathecal 
a
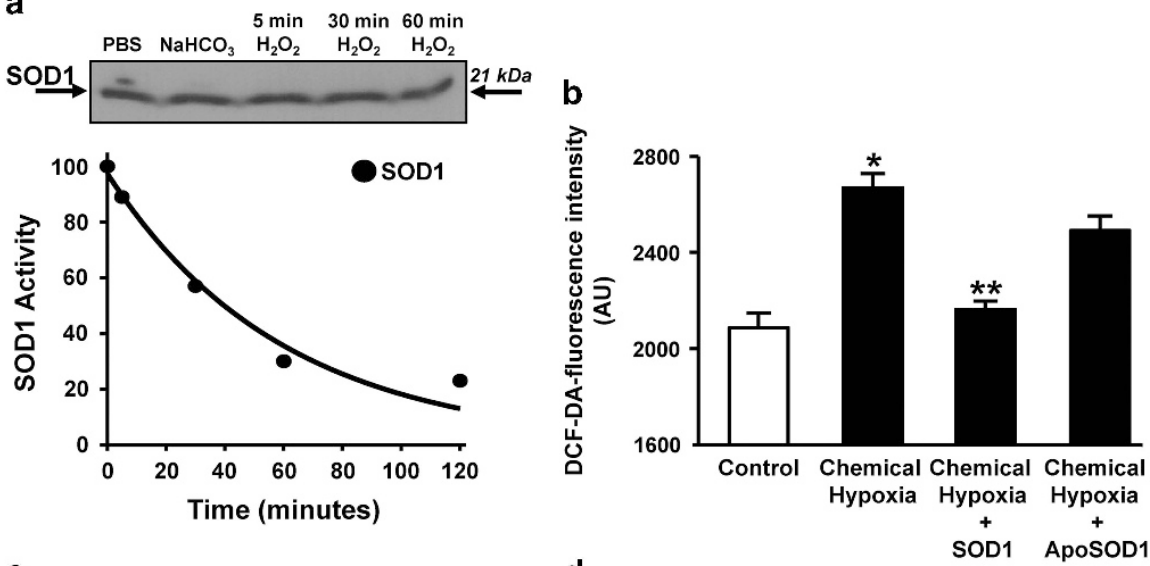

C

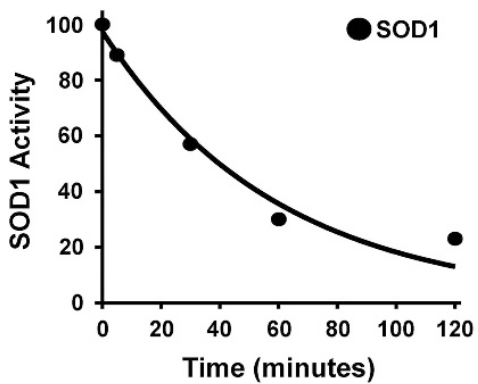

d
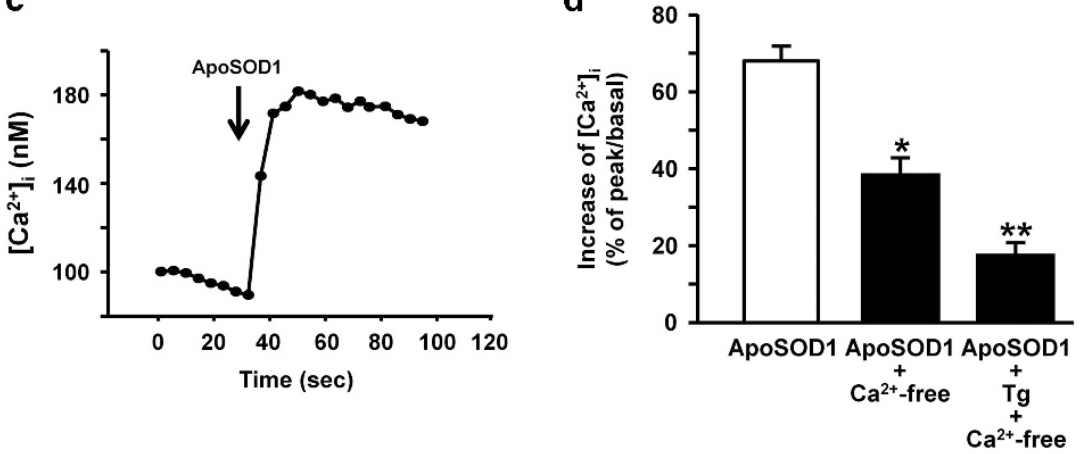

e Control SOD1 ApoSOD1

f
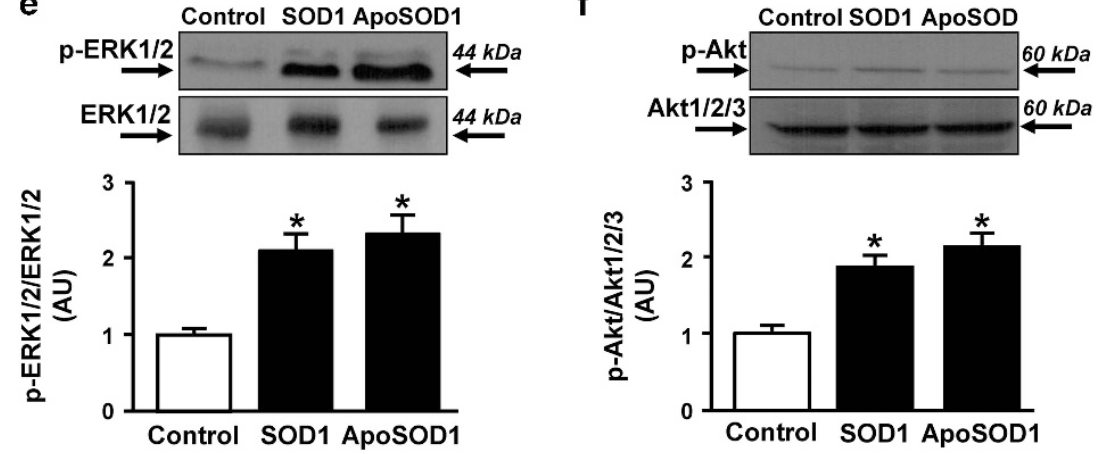

Figure 4 Effects of ApoSOD1 on $\mathrm{Ca}^{2+} / \mathrm{Akt} / \mathrm{ERK} 1 / 2$ signaling pathway in NSC-34 motor neurons. (a) (Top) Western blotting of SOD1 expression after inactivation with $\mathrm{H}_{2} \mathrm{O}_{2}$ $(200 \mathrm{mM})$ for several time points. (Bottom) Representative curve of the time-dependent inactivation of SOD1 in $\mathrm{H}_{2} \mathrm{O}_{2}$. (b) Bar graph depicting DCF-DA-detected ROS production in NSC-34 motor neurons exposed to chemical hypoxia in the absence and in the presence of SOD1 (400 ng/ml) or ApoSOD1 (400 ng/ml). Data are expressed as mean \pm S.E. of three different experiments. ${ }^{*} P<0.05$ versus control; ${ }^{* *} P<0.05$ versus chemical hypoxia and chemical hypoxia+ApoSOD1. (c and $\left.\mathbf{d}\right)$ Single-cell trace depicting $\left[\mathrm{Ca}^{2+}{ }^{2}\right.$; before and after ApoSOD1 administration (c). Quantification of the effect of ApoSOD1, ApoSOD1 in $\mathrm{Ca}^{2+}$-free and ApoSOD1 in $\mathrm{Ca}^{2+}$-free+thapsigargin $(\mathrm{Tg})$ on $\left[\mathrm{Ca}^{2+}{ }_{\mathrm{i}}\right.$ (d). $\mathrm{ApoSOD}$ significantly increases $\left[\mathrm{Ca}^{2+}\right]_{\mathrm{i}}$. Data are expressed as mean \pm S.E. of three different experiments performed on 60 cells. ${ }^{\star} P<0.05$ versus ApoSOD1. ${ }^{* \star} P<0.05$ versus ApoSOD1 $+\mathrm{Ca}^{2+}$-free. (e) Representative western blotting and quantification of the effect of SOD1 and ApoSOD1 (400 ng/m//10 min) on p-ERK1/2 and ERK1/2 expression. Data are expressed as mean \pm S.E. of three different experimental sessions. ${ }^{*} P<0.05$ versus control. (f) Representative western blotting and quantification of the effect of SOD1 and ApoSOD1 (400 ng/ml/10 min) on p-Akt and Akt1/2/3 expression. Data are expressed as mean \pm S.E. of three different experimental sessions. ${ }^{*} P<0.05$ versus control

treatment with $\mathrm{hSOD} 1^{\mathrm{wt}}$ delays disease progression and prolongs survival in SOD $1{ }^{\mathrm{G} 93 \mathrm{~A}}$ rats. ${ }^{6}$ On the other hand, it has been shown that SOD1 aggregates causing motor neuronal death are trimers of partially unfolded species of wild-type and mutated SOD1. ${ }^{9,11}$ In particular, perturbation of environmental conditions (i.e., low $\mathrm{pH}$ ) as well as the expression of diseaseassociated mutants induce dissociation of SOD1 dimers in apomonomers able to form these toxic trimers. ${ }^{9}$ Accordingly, the phosphomimetic mutation T2D of SOD1, which thermodynamically stabilizes the native dimer, reduces cell death induced by SOD $1^{\mathrm{A} 4 \mathrm{~V}}$, one of the most aggressive ALSassociated mutation in North America. ${ }^{25}$ Therefore, the administration of stabilized SOD1 native conformation or ApoSOD1 may offer new perspectives in ALS therapy.

Another critical point in our study is related to the mode of action of SOD1 at the level of motor neurons exposed to the cycad neurotoxin L-BMAA. In this respect, the neuroprotective action exerted by SOD1 on motor neurons does not depend on 

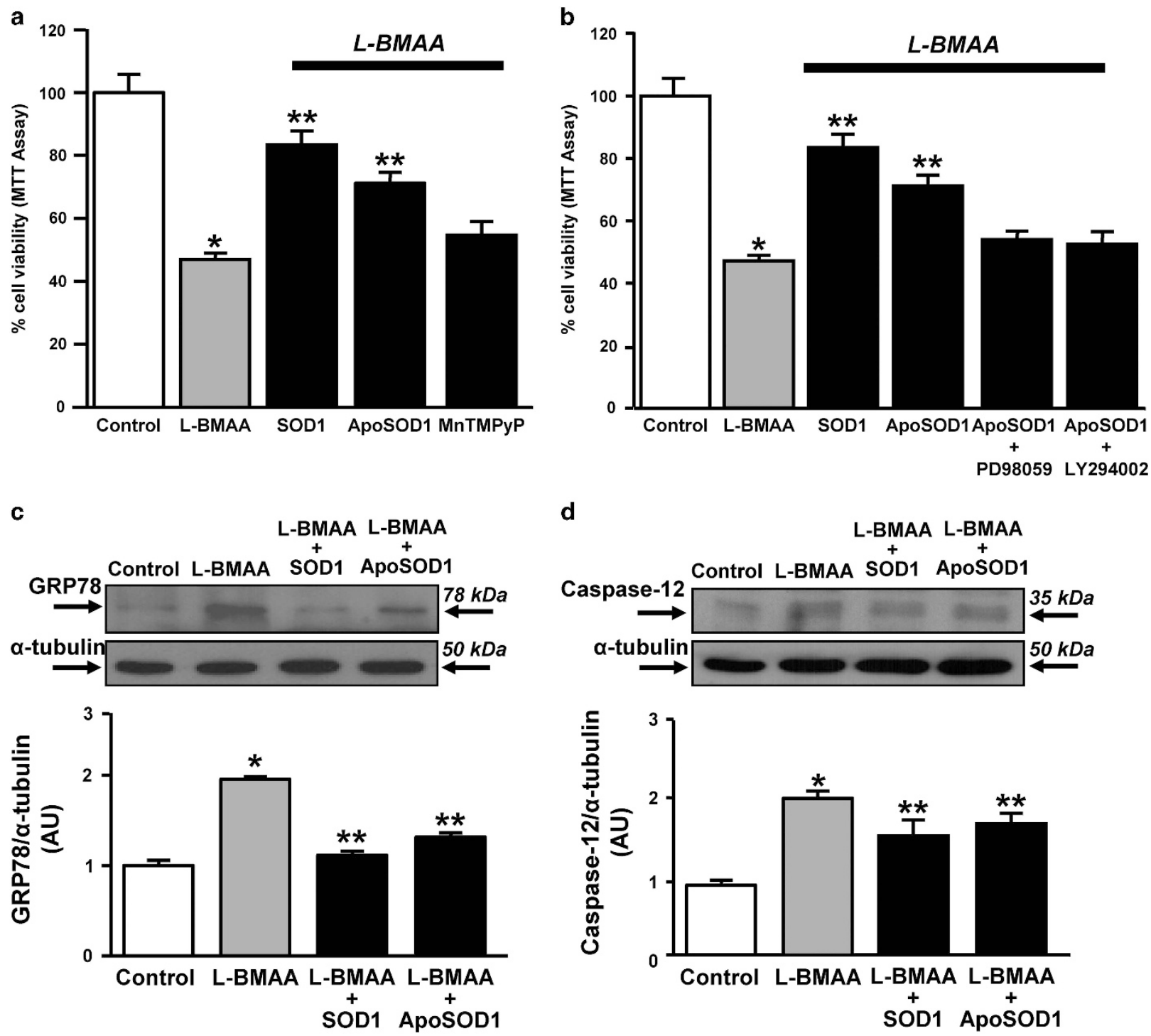

Figure 5 Effect of SOD1 and ApoSOD1 on ER stress induced by L-BMAA in NSC-34 motor neurons. (a) Bar graph depicting the effect of SOD1, ApoSOD1 and MnTMPyP on L-BMAA-induced cell death measured by MTT. SOD1, ApoSOD1 and MnTMPyP were preincubated 10 min before the exposure to the cycad toxin (300 $\mu \mathrm{M} / 48 \mathrm{~h})$. (b) Bar graph depicting the effect of L-BMAA (300 $\mu \mathrm{M} / 48 \mathrm{~h}$ ) on cell death of NSC-34 motor neurons pretreated with PD98059 or LY294002 and then exposed to ApoSOD1 (400 $\mathrm{ng} / \mathrm{ml} / 10 \mathrm{~min})$. Data are expressed as mean \pm S.E. of three different experimental sessions. ${ }^{*} P<0.05$ versus its respective control; ${ }^{* *} P<0.05$ versus L-BMAA alone and the other treatments. (c and d) Representative western blottings and quantification of the effect of L-BMAA on GRP78 (C) and caspase-12 (D) expression in the absence or presence of SOD1 or ApoSOD1 (400 ng/ml/10 min). Data are expressed as mean \pm S.E. of three different experimental sessions. ${ }^{*} P<0.05$ vs control; ${ }^{* *} P<0.05$ versus L-BMAA alone

its dismutase activity but may be attributed to the rapid activation of the survival Akt/ERK1/2 signaling pathway. The rapidity of the effect on $\left[\mathrm{Ca}^{2+}\right]_{i}$ increase seems to suggest that SOD1 could activate a plasma membrane mechanism not yet dentified. On the other hand, the occurrence of SOD1 uptake has been already demonstrated by the groups of Yerbury and Atkin. ${ }^{23,24}$ However the involvement of this mechanism in the activation of the prosurvival Akt/ERK1/2 signaling pathway cannot be considered as it occurred in 30-60 min, whereas $\left[\mathrm{Ca}^{2+}\right]_{\mathrm{i}}$ increase and Akt and ERK1/2 phosphorylation were demonstrated, in our study, at earlier times.

In conclusion, this paper further substantiates previous studies reporting that the modification in SOD1 dismutase activity is not responsible for the development of motor neuron degeneration. However, its greater merit lies in having identified the transduction signaling pathway underlying the neuroprotective effect of ApoSOD1, the $\mathrm{Ca}^{2+} / \mathrm{Akt} / \mathrm{ERK} 1 / 2$ signaling pathway that eventually may lead to new therapeutic targets for the different forms of ALS.

\section{Materials and Methods}

Reagents. Media and sera for cell cultures were purchased from Invitrogen (Milan, Italy); antibiotics for cell cultures were from Sigma-Aldrich (St. Louis, MO, USA). Mouse monoclonal antibody against p-ERK $1 / 2$, rabbit polyclonal antibody against ERK1/2, and rabbit polyclonal antibody against Akt1/2/3 were from Santa Cruz Biotechnology, Inc. (Santa Cruz, CA, USA); mouse monoclonal p-Akt antibody, rabbit polyclonal GRP78 antibody and rabbit polyclonal caspase-12 antibody were from Cell Signaling Technology Inc. (Danvers, MA, USA); mouse monoclonal SMI-32 antibody was from Covance-Signet (San Diego, CA, USA); mouse 
a
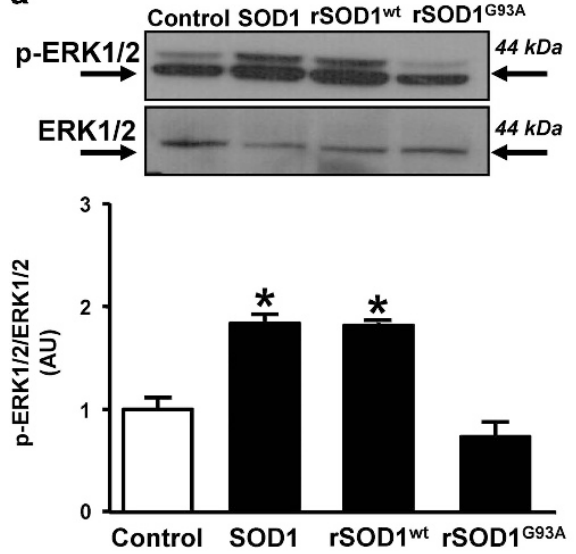

b
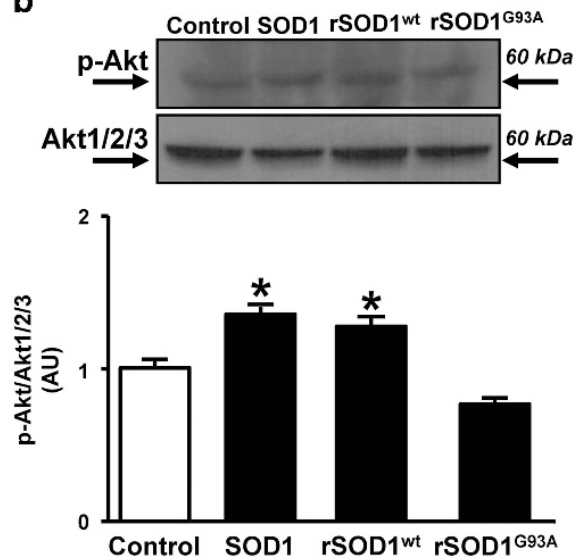

C

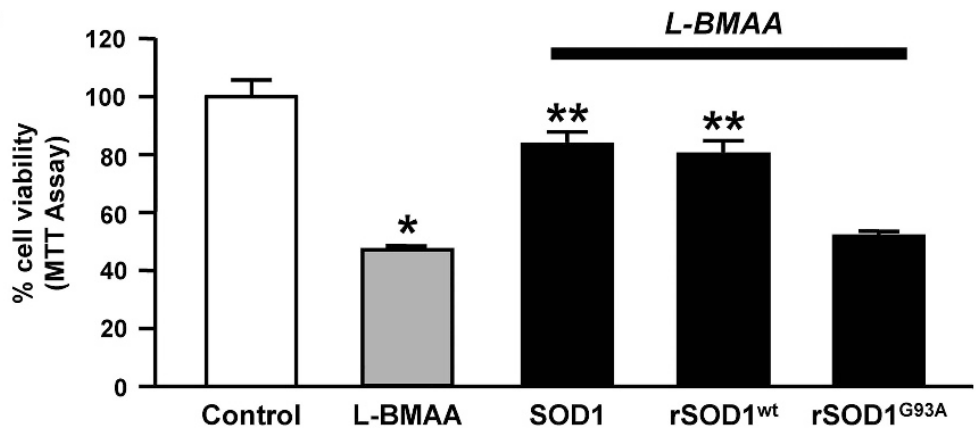

Figure 6 Effects of the recombinant SOD1 ${ }^{\text {G93A }}$ on Akt/ERK1/2 signaling pathway and on cell survival in NSC-34 motor neurons exposed to L-BMAA. (a) Representative western blotting and quantification of the effect of SOD1, rSOD $1^{\mathrm{wt}}$ and rSOD ${ }^{\mathrm{G} 93 \mathrm{~A}}(400 \mathrm{ng} / \mathrm{ml} / 10 \mathrm{~min})$ on $\mathrm{p}$-ERK $1 / 2$ and ERK $1 / 2$ expression. (b) Representative western blotting and quantification of the effect of SOD1, rSOD ${ }^{\text {wt }}$ and rSOD ${ }^{\mathrm{G} 93 \mathrm{~A}}(400 \mathrm{ng} / \mathrm{ml} / 10 \mathrm{~min})$ on p-Akt and Akt1/2/3 expression. (a and $\left.\mathbf{b}\right)$ Data are expressed as mean $\pm \mathrm{SE}$ of three different experimental sessions. ${ }^{*} P<0.05$ versus control and rSOD1 ${ }^{\mathrm{G} 93 \mathrm{~A}}$. (c) Bar graph depicting the effect of L-BMAA ( $\left.300 \mu \mathrm{M} / 48 \mathrm{~h}\right)$ on cell death, measured by MTT, of NSC-34 motor neurons pretreated with SOD1, rSOD $1^{\text {wt }}$ and $\mathrm{rSOD} 1^{\mathrm{G} 93 \mathrm{~A} A}(400 \mathrm{ng} / \mathrm{ml} / 10 \mathrm{~min})$. Data are expressed as mean \pm S.E. of three different experimental sessions. ${ }^{*} P<0.05$ versus control; ${ }^{* *} P<0.05$ versus L-BMAA alone and rSOD $1{ }^{\text {G93A }}$

monoclonal $\beta$-tubulin antibody was from Sigma-Aldrich. Western blotting, ECL reagents and chemicals were from GE Healthcare (Milan, Italy). The inactive mutant HA-Aktk179M (Akt D -) plasmids were donated by P. Formisano ("Federico II" University of Naples, Naples, Italy). siRNA-MEK1 and siRNA-Control were purchased from Dharmacon RNA Technologies (Thema Ricerca, Italy). SOD1, retinoic acid, L-BMAA, thapsigargin, $\mathrm{H}_{2} \mathrm{O}_{2}, \mathrm{LY} 294002$, PD98059, fluorescein diacetate (FDA), propidium iodide (PI) and all other reagents were from Sigma (Milan, Italy). MnTMPyP pentachloride was purchased from Santa Cruz Biotechnology. 1-[2-(5-Carboxyoxazol-2-yl)-6-aminobenzofuran-5-oxy]-2-(21-amino51-methylphenoxy)-ethane- $N, N, N 1, N 1$-tetraacetic acid penta-acetoxymethyl ester (Fura-2/AM) was from Molecular Probes (Invitrogen Italia, Milan, Italy).

Cell cultures. NSC-34 cells were grown in monolayer in Dulbecco's Modified Eagles Medium containing $4.5 \mathrm{~g} / \mathrm{l}$ glucose, supplemented with $10 \%$ fetal bovine serum (FBS), $2 \mathrm{mM} \mathrm{L-glutamine,} 100 \mathrm{IU} / \mathrm{ml}$ penicillin and $100 \mu \mathrm{g} / \mathrm{ml}$ streptomycin. The cells were kept in a $5 \% \mathrm{CO}_{2}$ and $95 \%$ air atmosphere at $37^{\circ} \mathrm{C}$. Before each experiment, NSC-34 cells were differentiated in $10 \mu \mathrm{M}$ retinoic acid for $48 \mathrm{~h}$. These cells display a multipolar neuron-like phenotype, express choline acetyltransferase and neurofilament triplet proteins and generate action potentials. ${ }^{26}$

Mouse and rat motor neuronal primary cultures. Motor neuronenriched cultures were prepared from spinal cord of 12-14-day-old C57BL/6 wildtype mouse embryos. Briefly, mice were anesthetized and then killed by cervical dislocation; spinal cords were then isolated from each embryo. Dissection and dissociation were performed in $\mathrm{MgSO}_{4}$-phosphate-buffered saline (PBS) containing penicillin and streptomycin. Tissues were dissociated by trituration and centrifuged for $2 \mathrm{~min}$ at 1000 r.p.m. Then tissues were incubated with trypsin for $20 \mathrm{~min}$ in a $37{ }^{\circ} \mathrm{C}$ water bath with agitation. After that, tissues were treated with $\mathrm{MgSO}_{4}-\mathrm{PBS}$ containing penicillin and streptomycin, DNase and trypsin. After centrifugation for
2 min at 1000 r.p.m., tissues were incubated again with DNase and trypsin in $\mathrm{MgSO}_{4}$-PBS containing penicillin and streptomycin and then the cells were separated by density gradient. Finally, cells were centrifuged for $10 \mathrm{~min}$ at 1000 r.p. $\mathrm{m}$. and plated at $8 \times 10^{4}$ on glass coverslip precoated with poly-D-lysine $(20 \mu \mathrm{g} / \mathrm{ml})$ in Neuron Basal Medium (Life Technologies, Milan, Italy), supplemented with B27 and $2 \mathrm{mM} \mathrm{L-glutamine.}$

Rat motor neuron-enriched cultures were prepared from the spinal cord of 12-14day-old Wistar embryos. Briefly, each embryo was decapitated at the infracranial notch to isolate spinal cords. Then tissues were dissociated in a trypsin solution and incubated for $15 \mathrm{~min}$ at $37^{\circ} \mathrm{C}$. After that, tissues were further dissociated and settled in Leibovitz's L-15 medium supplemented with $0.2 \%$ bovine serum albumin (BSA), $5 \%$ FBS and $0.02 \%$ DNase. Supernatants were then collected in L-15 fresh medium, resuspended slowly on the top of a cushion of $4 \%$ BSA and centrifuged at 1000 r.p.m. for 10 min. Pellets were resuspended in L-15 medium and collected with the supernatants obtained from the trituration of the remaining tissue in L-15 medium supplemented with $0.4 \%$ BSA and $0.004 \%$ DNase. Finally, all the suspension was centrifuged at 1000 r.p.m. for $10 \mathrm{~min}$. Cells were plated at $5 \times 10^{4} \mathrm{cells} / \mathrm{ml}$ in tissue culture plates precoated with polyD-lysine $(20 \mu \mathrm{g} / \mathrm{ml})$ in Neuron Basal Medium (Gibco, Life Technologies), supplemented as previously described. ${ }^{27}$ Cytosine $\beta$-D-arabinofuranoside hydrochloride $(10 \mu \mathrm{M})$ was added at 4 and $8 \mathrm{DIV}$ for $48 \mathrm{~h}$ to prevent non-neuronal cell growth.

All motor neuronal primary cultures were cultured at $37^{\circ} \mathrm{C}$ in a humidified $5 \% \mathrm{CO}_{2}$ atmosphere and used after 10-12 days of culture. All the experiments were performed according to the procedures described in experimental protocols approved by the Ethical Committee of "Federico II" University of Naples.

SOD1 release. After differentiation in $10 \mu \mathrm{M}$ retinoic acid for $48 \mathrm{~h}$, NSC-34 motor neurons were exposed for $10 \mathrm{~min}$ to a Normal Krebs solution containing (in mM) $5.5 \mathrm{KCl}, 100 \mathrm{NaCl}, 1.2 \mathrm{MgCl}_{2}, 1.5 \mathrm{CaCl}_{2}, 10$ glucose and $10 \mathrm{Hepes}-\mathrm{KOH}$ $\mathrm{pH} 7.4$ or to a high $\mathrm{K}^{+}$solution containing (in $\mathrm{mM}$ ) $55 \mathrm{KCl}, 95 \mathrm{NaCl}, 1.2 \mathrm{MgCl}_{2}, 1.5$ 
$\mathrm{CaCl}_{2}, 10$ glucose and 10 HEPES-NaOH, pH 7.4 in the absence or presence of ethylene glycol-bis( $\beta$-aminoethylether)- $N, N, N, N$-tetraacetic acid (EGTA, $1 \mathrm{mM}$ ). At the end, supernatants were collected and analyzed by western blotting.
SOD1, ApoSOD1 and L-BMAA treatments. NSC-34 motor neurons were plated in multiple well cluster plates and differentiated, as previously described. After differentiation, the culture medium was replaced with fresh medium a

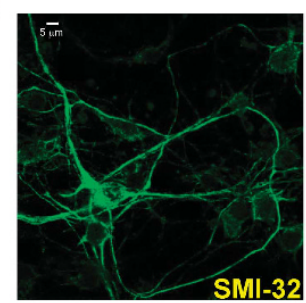

b

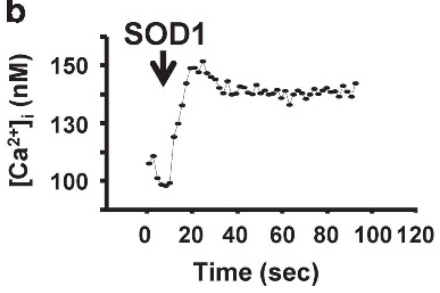

d

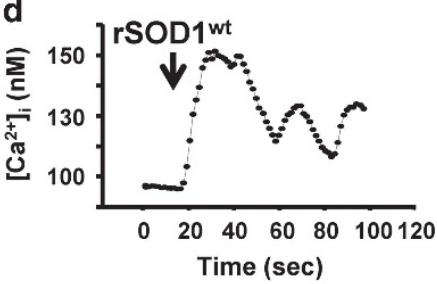

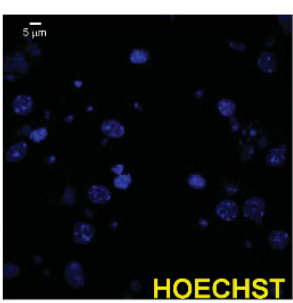

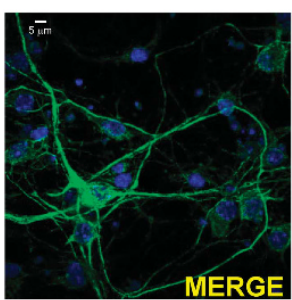

C
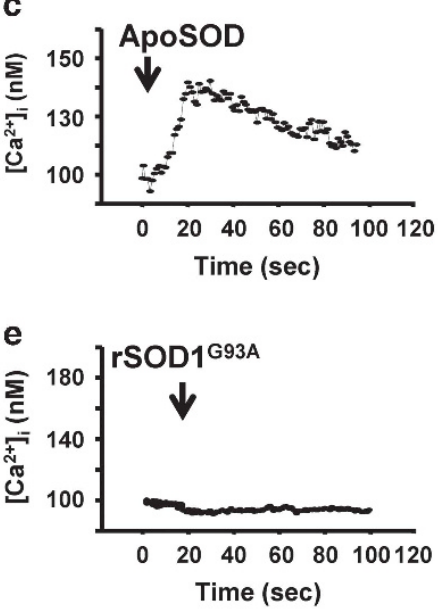

f
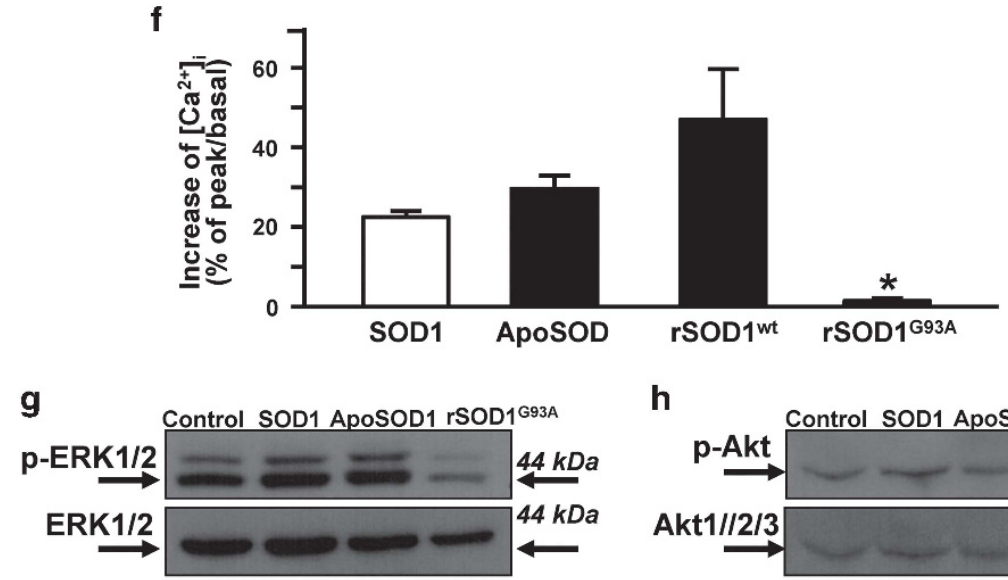

h
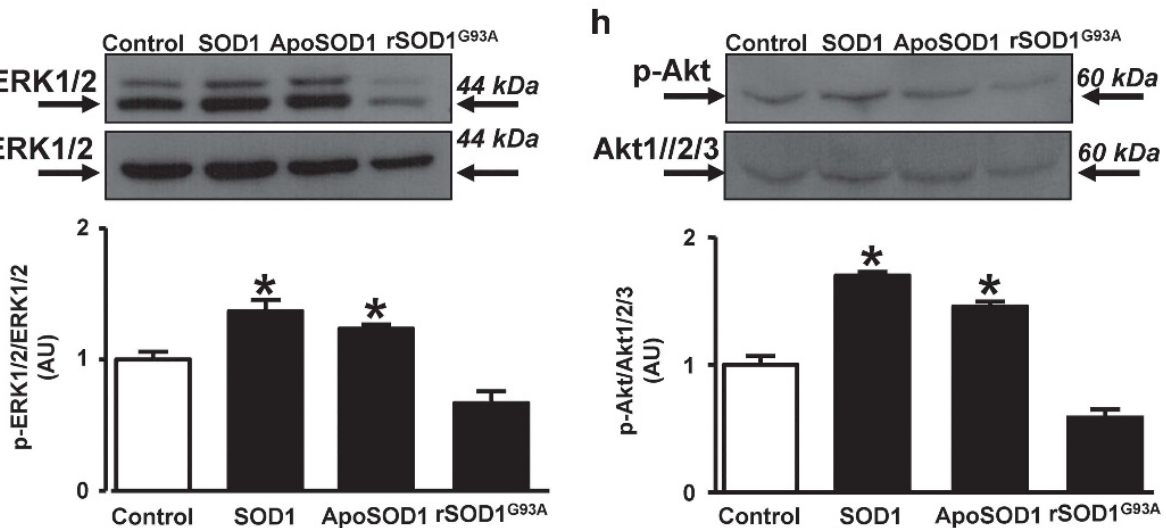

Figure 7 Effects of ApoSOD1, SOD1, rSOD1 $1^{\text {wt }}$ and $\mathrm{rSOD} 1{ }^{\mathrm{G} 93 \mathrm{~A}}$ on $\mathrm{Ca}^{2+} / \mathrm{Akt} / \mathrm{ERK} 1 / 2$ signaling pathway in rat primary motor neurons. (a) Immunocytochemical images of SMI-32 and Hoechst. (b-f) Representative single-cell traces (b-e) and quantification (f) of the effect on $\left[\mathrm{Ca}^{2+}\right]_{\text {i }}$ of SOD1 (b), ApoSOD1 (c), rSOD ${ }^{\text {wt }}$ (d) and rSOD1 ${ }^{\mathrm{G} 93 \mathrm{~A}}(\mathbf{e})$, all at $400 \mathrm{ng} / \mathrm{ml}$ in normal Krebs solution. Data are expressed as mean \pm S.E. of three different experiments performed on 30/50 cells for each group. ${ }^{*} P<0.05$ versus SOD1, ApoSOD1, rSOD1 ${ }^{\text {wt }}$. (g) Representative western blotting and quantification of the effect of SOD1, ApoSOD1 and rSOD $1^{\mathrm{G} 93 \mathrm{~A}}$ (400 $\mathrm{ng} / \mathrm{ml} / 10 \mathrm{~min}$ ) on p-ERK1/2 and ERK1/2 expression. (h) Representative western blotting and quantification of the effect of SOD1, ApoSOD1 and rSOD1 ${ }^{\text {G93A }}$ (400 ng/ml/10 min) on p-Akt and Akt1/2/3 expression. $(\mathbf{g}$ and $\mathbf{h})$ Data are expressed as mean \pm S.E. of three different experimental sessions. ${ }^{*} P<0.05$ versus its respective control and rSOD $1^{\mathrm{G} 93 \mathrm{~A}}$ 
a

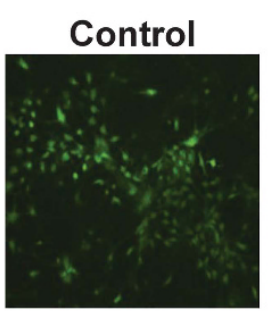

L-BMAA 24h

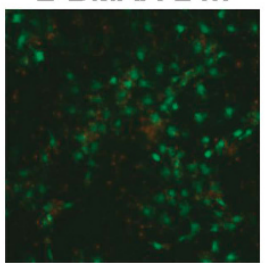

L-BMAA 48h
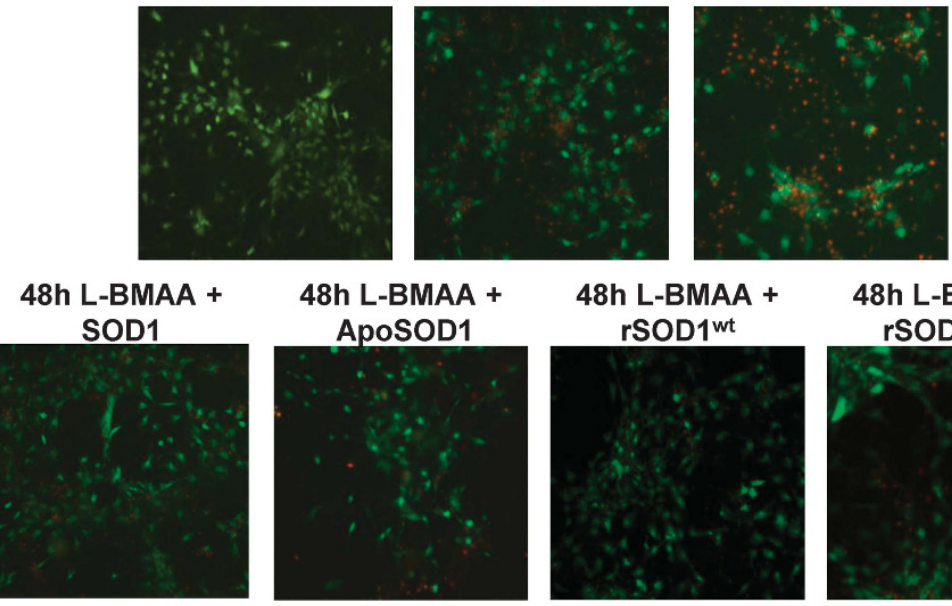

48h L-BMAA +

48h L-BMAA + rSOD1wt
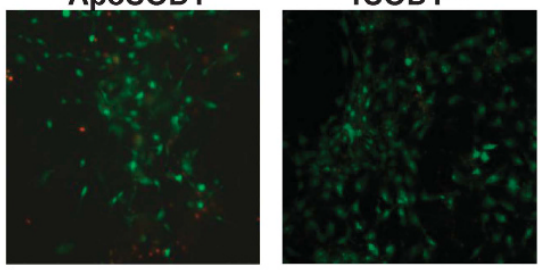

48h L-BMAA + rSOD1G93A

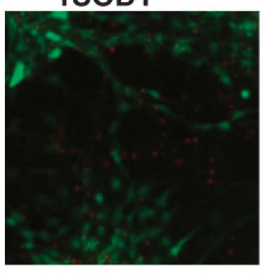

b

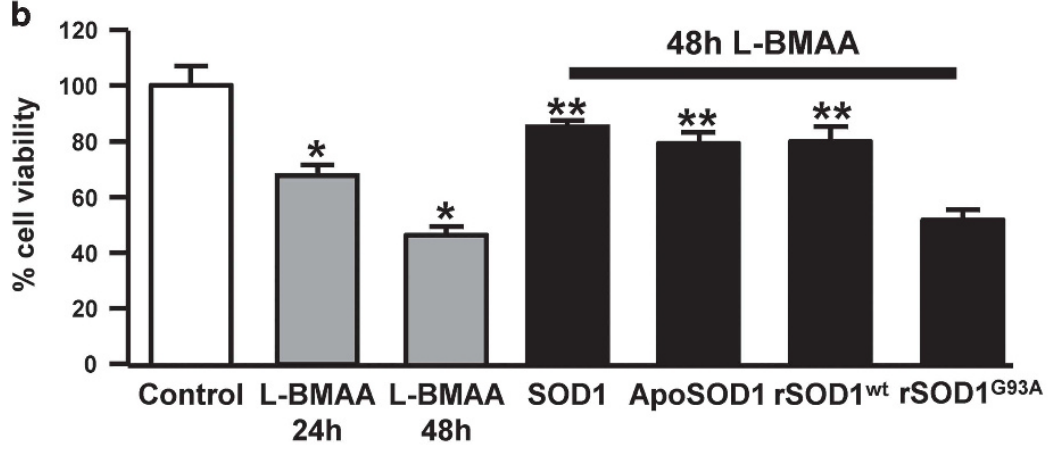

C

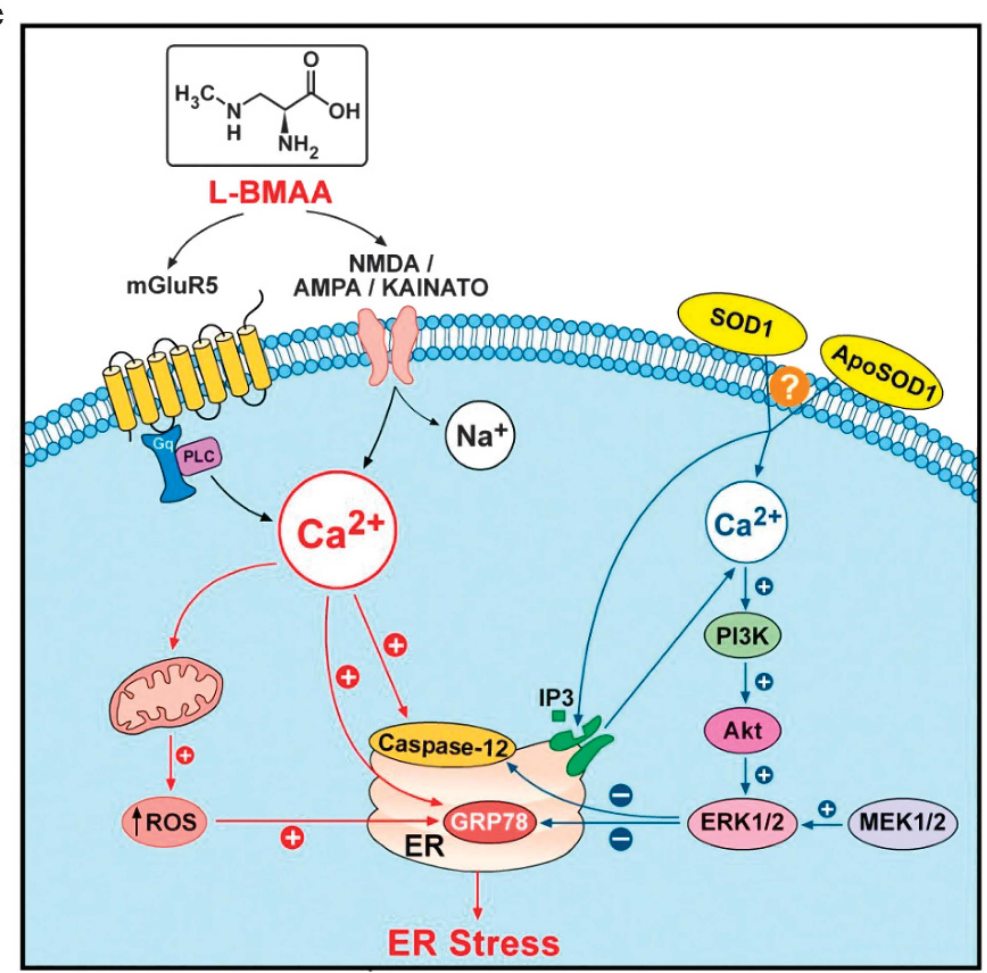


containing L-BMAA $(300 \mu \mathrm{M} / 48 \mathrm{~h})$. Ten minutes before L-BMAA addition, SOD1 $(400 \mathrm{ng} / \mathrm{ml})$ or ApoSOD1 $(400 \mathrm{ng} / \mathrm{ml})$ were administered in fresh cell culture medium $(\mathrm{pH} 7.4)$ to preserve SOD1 degradation by extracellular proteases. ${ }^{28}$

Immunocytochemistry. Mouse monoclonal SMI-32 antibody (CovanceSignet) was used to characterize differentiated NSC-34 motor neurons and primary motor neurons by immunocytochemistry. NSC-34 cells were cultured on glass coverslips and differentiated, while primary cultures of motor neurons were cultured on glass coverslips for 12 days. Then the cells were rinsed twice in cold $0.01 \mathrm{M}$ saline phosphate buffer at pH 7.4 (PBS) and fixed in 4\% (w/v) paraformaldehyde (Sigma) for $20 \mathrm{~min}$ at room temperature (RT). After three PBS washes, cells were blocked with $3 \%$ (w/v) BSA and 0.05\% Tryton-X (Bio-Rad, Milan, Italy) for $1 \mathrm{~h}$ at RT. The coverslips were then incubated with the primary antibody anti-SMI-32 (1:1 000 diluition) at $4^{\circ} \mathrm{C}$ overnight. After three washes in PBS, the coverslips were incubated in the dark with the secondary antibody, Alexa-fluor 488 anti-mouse IgG (Molecular Probes, Eugene, OR, USA; dilution 1:200) for $1 \mathrm{~h}$ at RT. After the final wash, the coverslips and the cells were mounted with Vectashield (Vector Laboratories, Burlingame, CA, USA) and analyzed with a Nikon Eclipse 400 upright microscope (Nikon Instruments, Florence, Italy), equipped with a CCD digital camera (Coolsnap-Pro, Media Cybernetics, Silver Springs, MD, USA) and Image Pro-Plus software (Media Cybernetics).

$\left[\mathrm{Ca}^{2+}\right]_{\mathbf{i}}$ measurements. $\left[\mathrm{Ca}^{2+}\right]_{\mathrm{i}}$ was measured by single-cell computerassisted video imaging. ${ }^{29}$ Briefly, at the end of the Fura-2/AM loading period, the coverslips were placed into a perfusion chamber (Medical System, Co. Greenvale, NY, USA) mounted onto a Zeiss Axiovert 200 microscope (Carl Zeiss, Zena, Germany) equipped with a FLUAR 40X oil objective lens. The experiments were carried out with a digital imaging system composed of MicroMax 512BFT cooled CCD camera (Princeton Instruments, Trenton, NJ, USA), LAMBDA 10-2 filter wheeler (Sutter Instruments, Novato, CA, USA) and Meta-Morph/MetaFluor Imaging System software (Universal Imaging, West Chester, PA, USA). All the results are presented as cytosolic $\mathrm{Ca}^{2+}$ concentration. Assuming that the $\mathrm{Kd}$ for Fura-2 was $224 \mathrm{nM}$, the equation of Grynkiewicz et al., ${ }^{30}$ whose parameters were determined for individual cells as described by Urbanczyk et al., ${ }^{31}$ was used for calibration.

Cell transfection. Transfection of NSC-34 motor neurons was carried out in Optimem medium using HyPerFect Transfection Reagent (Qiagen, Milan, Italy).

Western blotting. After treatments, cells were washed in PBS and lysed by gentle scraping in ice-cold lysis buffer containing $20 \mathrm{mM}$ Tris- $\mathrm{HCl}(\mathrm{pH} 7.5), 10 \mathrm{mM}$ $\mathrm{NaF}, 1 \mathrm{mM}$ phenylmethylsulfonyl fluoride, $1 \%$ NONIDET P- $40,1 \mathrm{mM} \mathrm{Na}_{3} \mathrm{VO}_{4}, 0.1 \%$ aprotinin, $0.7 \mathrm{mg} / \mathrm{ml}$ pepstatin and $1 \mu \mathrm{g} / \mathrm{ml}$ leupeptin. Protein concentration was determined by the Bradford method. ${ }^{32}$

For p-Akt, Akt1/2/3, p-ERK1/2, ERK1/2, GRP78 and caspase-12 expression, proteins $(50 \mu \mathrm{g})$ were separated on $10 \%$ SDS-polyacrylamide gels and transferred onto Hybond ECL nitrocellulose membranes (Amersham, Milan, Italy). Membranes were blocked with $5 \%$ non-fat dry milk in $0.1 \%$ Tween 20 (Sigma-Aldrich; $2 \mathrm{mM}$ Tris$\mathrm{HCl}$ and $50 \mathrm{mM} \mathrm{NaCl}, \mathrm{pH} \mathrm{7.5)}$ for $2 \mathrm{~h}$ at room temperature; then membranes were incubated overnight at $4{ }^{\circ} \mathrm{C}$ in blocking buffer containing monoclonal antibodies (1:1000) against p-Akt (Cell Signaling Technology Inc.) and p-ERK1/2 (Santa Cruz Biotecnology, Inc.), rabbit polyclonal antibodies (1:1000) against GRP78 (Cell Signaling Technology Inc.) or rabbit polyclonal antibodies (1: 1000) against caspase12 (Cell Signaling Technology Inc.). All membranes were re-blotted in the blocking buffer with the 1:1000 monoclonal antibodies against $\beta$-tubulin (Sigma-Aldrich), with the 1:1000 polyclonal antibodies against Akt1/2/3 (Santa Cruz Biotecnology, Inc.) or with the 1:1000 polyclonal antibodies against ERK1/2 (Santa Cruz Biotecnology, Inc.).

Immunoreactive bands were detected with the ECL reagent (Amersham). The optical density of the bands was determined by Chemi-Doc Imaging System (Bio-Rad, Hercules, CA, USA).
Cell death. Mitochondrial activity was evaluated by the MTT (3[4,5-dimethylthiazol-2-yl]-2,5-diphenyl-tetrazolium bromide) assay as already reported. The data were expressed as a percentage of cell viability of control cultures. Cell death was also evaluated by measuring the ratio between dead and living cells as already reported. ${ }^{29}$ To quantify cell death after the experimental procedures, primary motor neurons were washed with normal Krebs and double stained with $36 \mu \mathrm{M}$ FDA and $7 \mu \mathrm{M} \mathrm{PI}$ for $20 \mathrm{~min}$ at $37^{\circ} \mathrm{C}$ in a phosphate buffer solution. Stained cells were examined immediately with a standard inverse fluorescence microscope at 480 and $546 \mathrm{~nm}^{33} \mathrm{Pl}$ - and FDA-positive cells were counted in three representative highpower fields of independent cultures, and cell death was determined by the ratio of the number of PI-positive cells/PI+FDA-stained positive cells.

Chemical hypoxia. Chemical hypoxia was reproduced by adding the following chemical inhibitors to the culture medium for $45 \mathrm{~min}: 5 \mu \mathrm{g} / \mathrm{ml}$ oligomycin (a oxidative phosphorylation inhibitor) plus $2 \mathrm{mM}$ 2-deoxyglucose (a glycolis inhibitor) in glucose-free medium composed of $145 \mathrm{mM} \mathrm{NaCl}, 5.5 \mathrm{mM} \mathrm{KCl}, 1.2 \mathrm{mM} \mathrm{MgCl}_{2}$, $1.5 \mathrm{mM} \mathrm{CaCl}_{2}$ and $10 \mathrm{mM} \mathrm{HEPES}$, pH 7.4, as previously described. ${ }^{33}$

ROS production. DCFH-DA, a cell membrane-permeable fluorescein analog, was used to detect ROS production ${ }^{34}$ in differentiated NSC-34 motor neurons. At the end of the experiments, cells were viewed with a Nikon Eclipse 400 upright microscope (Nikon Instruments) equipped with a CCD digital camera (CoolsnapPro, Media Cybernetics).

SOD1 inactivation. SOD1 was incubated with $\mathrm{H}_{2} \mathrm{O}_{2}(200 \mathrm{mM})$ in $25 \mathrm{mM}$ sodium bicarbonate buffer (pH 7.5) for 5, 30, 60 and $120 \mathrm{~min}$ at room temperature. The reaction was then stopped by adding catalase $(1000 \mathrm{U} / \mathrm{ml})$ for $30 \mathrm{~min}$ at $37^{\circ} \mathrm{C}$. Finally, SOD1 activity was measured by the SOD assay kit, purchased from Sigma. This kit uses Dojindo's highly water-soluble tetrazolium salt, WST-1 (2-(4-iodophenyl)-3-(4-nitrophenyl)-5-(2,4-disulfophenyl)-2H-tetrazolium, monosodium salt), which produces a water-soluble formazan dye upon reduction with a superoxide anion. The reduction rate with $\mathrm{O}_{2}$ is linearly related to the xanthine oxidase activity and is inhibited by SOD; therefore, the $\mathrm{IC}_{50}$ of $\mathrm{SOD}$ activity can be determined by a colorimetric method. In brief, because the absorbance at $440 \mathrm{~nm}$ is proportional to the amount of superoxide anion, SOD inhibition activity can be quantified by measuring the decrease in color development at $440 \mathrm{~nm}$.

Statistical analysis. Data are expressed as mean \pm S.E.M. Statistical comparisons between controls and treated experimental groups were performed using the one-way ANOVA, followed by Newman Keul's test. $P<0.05$ was considered statistically significant.

\section{Conflict of Interest}

The authors declare no conflict of interest.

Acknowledgements. This work was supported by PON03PE_00146_1 by MIUR to L.A. and Progetto Giovani Ricercatori GR-2010-2318138 from Ministero della Salute to A. Secondo. POR Campania FESR 2007-2013MOVIE (B25C1300024007) to A. Secondo We thank Professor Neil Cashman for the gift of NSC-34 cells and Dr. Paola Merolla for the editorial revision.

\section{Author contributions}

TP performed and analyzed experiments and contributed to writing the mnuscript. A Secondo planned experiments, performed and analyzed experiments and contributed to writing the mnuscript. VT, AE and MJS performed experiments. A Scorziello performed analysis. GFDR contributed to writing the mnuscript and helped co-authors to comment on the results. LA planned experiments, analyzed data and contributed

\section{4}

Figure 8 Effects of ApoSOD1, SOD1, rSOD1 ${ }^{\text {wt }}$ and $\mathrm{rSOD}^{\mathrm{G} 93 \mathrm{~A}}$ on L-BMAA-induced cell death in primary motor neurons. (a) Representative images depicting Pl- and fluoresceine-positive mouse motor neurons exposed to L-BMAA for 24 and $48 \mathrm{~h}$ in the absence or in the presence of SOD1, ApoSOD1, rSOD1 ${ }^{\text {wt }}$ and rSOD1 ${ }^{\text {G93A }}$ (400 ng/ml/ $10 \mathrm{~min}$ ). (b) Quantification of panel (a) as ratio of the number of PI-positive cells/PI+FDA-stained positive cells. ${ }^{*} P<0.05$ versus control; ${ }^{* *} P<0.05$ versus $\mathrm{L}$-BMAA at 24 and $48 \mathrm{~h}$ and versus L-BMAA+rSOD1 ${ }^{\mathrm{G} 93 \mathrm{~A}}$. (c) Scheme representing the effect of SOD1 in motor neurons on $\left[\mathrm{Ca}^{2+}\right]_{\text {, }}$, Akt/ERK1/2 transductional pathway and L-BMAA-induced ER-stress markers (GRP78 and caspase-12). The mechanism elicited by the cycad neurotoxin L-BMAA has been reported on the left 
to writing the manuscript. All experiments were performed at Federico II University of Naples, Naples, Italy.

1. Chou SM. Pathology-light microscopy of amyotrophic lateral sclerosis. In: Smith RA (ed). Handbook of Amyotrophic Lateral Sclerosis. Marcel Deckker Inc: New York, NY, USA, 1992 pp 133-181.

2. Rowland LP, Shneider NA. Amyotrophic lateral sclerosis. N Engl J Med 2001; 344: $1688-1700$.

3. Rosen DR, Siddique T, Patterson D, Figlewicz DA, Sapp P, Hentati A. Mutations in Cu/Zn superoxide dismutase gene are associated with familial amyotrophic lateral sclerosis. Nature 1993; 362: 59-62.

4. Renton AE, Chiò A, Traynor BJ. State of play in amyotrophic lateral sclerosis genetics. Nat Neurosci 2014; 17: 17-23.

5. Urushitani M, Ezzi SA, Matsuo A, Tooyama I, Juline JP. The endoplasmic reticulum-Golg pathway is a target for translocation and aggregation of mutant superoxide dismutase linked to ALS. FASEB J 2008; 22: 2476-2487.

6. Turner BJ, Atkin JD, Farg MA, Zang DW, Rembach A, Lopes EC et al. Impaired extracellular secretion of mutant superoxide dismutase 1 associates with neurotoxicity in familial amyotrophic lateral sclerosis. J Neurosci 2005; 25: 108-117.

7. Kong J, Xu Z. Massive mitochondrial degeneration in motor neurons triggers the onset of amyotrophic lateral sclerosis in mice expressing a mutant SOD1. J Neurosci 1998; 18 3241-3250.

8. Turner BJ, Atkin JD. ER stress and UPR in familial amyotrophic lateral sclerosis. Curr $\mathrm{Mol}$ Med 2006; 6: 79-86.

9. Proctor E, Fee L, Tao Y, Redler RL, Fay J, Zhang Y et al. Nonnative SOD1 trimer is toxic to motor neurons in a model of amyotrophic lateral sclerosis. Proc Natl Acad Sci 2016; 113 614-619.

10. Broom HR, Vassall KA, Rumfeldt JA, Doyle CM, Tong MS, Bonner JM et al. Combined isothermal titration and differential scanning calorimetry define three-state thermodynamics of fALS-associated mutant Apo SOD1 dimers and an increased population of folded monomer. Biochemistry 2016; 55: 519-533.

11. Khare SD, Caplow M, Dokholyan NV. The rate and equilibrium constants for a multistep reaction sequence for the aggregation of superoxide dismutase in amyotrophic lateral sclerosis. Proc Natl Acad Sci 2004; 101: 15094-15099.

12. Lindberg MJ, Tibell L, Oliveberg M. Common denominator of $\mathrm{Cu} / \mathrm{Zn}$ superoxide dismutase mutants associated with amyotrophic lateral sclerosis: decreased stability of the apo state. Proc Natl Acad Sci 2002; 99: 16607-16612.

13. Morita M, Aoki M, Abe K, Hasegawa T, Sakuma R, Onodera $Y$ et al. A novel two-base mutation in the $\mathrm{Cu} / \mathrm{Zn}$ superoxide dismutase gene associated with familial amyotrophic lateral sclerosis in Japan. Neurosci Lett 1996; 205: 79-82.

14. Andersen PM, Nilsson P, Keranen ML, Forsgren J, Hagglund M, Karlsborg LO et al. Phenotypic heterogeneity in motor neuron disease patients with CuZn-superoxide dismutase mutations in Scandinavia. Brain 1997; 120: 1723-1737.

15. Pick M, Rabani J, Yost F, Fridovich I. The catalytic mechanism of the manganese-containing superoxide dismutase of Escherichia coli studied by pulse radiolysis. J Am Chem Soc 1974; 96: 7329-7333.

16. Santillo M, Secondo A, Serù R, Damiano S, Garbi C, Taverna E et al. Evidence of calciumand SNARE-dependent release of CuZn superoxide dismutase from rat pituitary GH3 cells and synaptosomes in response to depolarization. J Neurochem 2007; 102: 679-685.

17. Mondola $\mathrm{P}$, Santillo $\mathrm{M}$, Serù $\mathrm{R}$, Damiano $\mathrm{S}$, Alvino $\mathrm{C}$, Ruggiero $\mathrm{G}$ et al. $\mathrm{Cu}, \mathrm{Zn}$ superoxide dismutase increases intracellular calcium levels via a phospholipase $C$-protein kinase $C$ pathway in SK-N-BE neuroblastoma cell. BBRC 2004; 324: 887-892.

18. McGuire V, Nelson LM. Epidemiology of ALS. In: Mitsumoto H, Przedborski S, Gordon PH (eds). Amyotrophic Lateral Sclerosis. Taylor \& Francis: New York, NY, USA 2006 pp 17-41.

19. Nozik-Grayck E, Suliman HB, Piantadosi CA. Extracellular superoxide dismutase. IJBCB 2005; 37: 2466-2471.
20. Borchelt DR, Lee MK, Slunt HS, Guarnieri M, Xu ZS, Wong PC et al. Superoxide dismutase 1 with mutations linked to familial amyotrophic lateral sclerosis possesses significant activity. Proc Natl Acad Sci USA 1994; 91: 8292-8296.

21. Gurney ME, Pu H, Chiu AY, Dal Canto MC, Polchow CY, Alexander DD et al. Motor neuron degeneration in mice that express a human $\mathrm{Cu}, \mathrm{Zn}$ superoxide dismutase mutation. Science 1994; 264: 1772-1775.

22. Reaume AG, Elliott JL, Hoffman EK, Kowall NW, Ferrante RJ, Siwek DF et al. Motor neurons in $\mathrm{Cu} / \mathrm{Zn}$ superoxide dismutase-deficient mice develop normally but exhibit enhanced cell death after axonal injury. Nat Genet 1996; 13: 43-47.

23. Sundaramoorthy V, Walker AK, Yerbury J, Soo KY, Farg MA, Hoang V et al. Extracellular wildtype and mutant SOD1 induces ER-Golgi pathology characteristic of amyotrophic lateral sclerosis in neuronal cells. Cell Mol Life Sci 2013; 70: 4181-4195.

24. Zeineddine R, Pundavela JF, Corcoran L, Stewart EM, Do-Ha D, Bax M et al. SOD1 protein aggregates stimulate macropinocytosis in neurons to facilitate their propagation. $\mathrm{Mol}$ Neurodegener 2015; 10: 57-73.

25. Fay JM, Zhu C, Proctor EA, Tao Y, Cui W, Ke H et al. A phosphomimetic mutation stabilizes SOD1 and rescues cell viability in the context of an ALS-associated mutation. Structure 2016; 24: 1898-1906.

26. Cashman N, Durham HD, Blusztajn JK, Oda K, Tabira T, Shaw IT et al. Neuroblastoma x spinal cord (NSC) hybrid cell lines resemble developing motor neurons. Dev Dyn 1992; 194: 209-221.

27. Graber DJ, Harris BT. Purification and culture of spinal motor neurons from rat embryosCold Spring Harb Protoc 2013; doi:10.1101/pdb.top070920.

28. De Stefano ME, Herrero MT. The multifaceted role of metalloproteinases in physiological and pathological conditions in embryonic and adult brains. Prog Neurobiol 2016; S0301-0082: 30100-30103.

29. Secondo A, Staiano RI, Scorziello A, Sirabella R, Boscia F, Adornetto A et al. BHK cells transfected with $\mathrm{NCX} 3$ are more resistant to hypoxia followed by reoxygenation than those transfected with NCX1 and NCX2: possible relationship with mitochondrial membrane potential. Cell Calcium 2007; 42: 521-535.

30. Grynkiewicz G, Poenie M, Tsien RY. A new generation of $\mathrm{Ca} 2+$ indicators with greatly improved fluorescence properties. J Biol Chem 1985; 260: 3440-3450.

31. Urbanczyk J, Chernysh O, Condrescu M, Reeves JP. Sodium-calcium exchange does not require allosteric calcium activation at high cytosolic sodium concentrations. J Physiol 2006; 575: 693-705.

32. Bradford MM. A rapid and sensitive method for the quantification of microgram quantities of protein utilizing the principle of protein-dye binding. Ann Biochem 1976; 72: 248-254.

33. Amoroso S, De Maio M, Russo GM, Catalano A, Bassi A, Montagnani $S$ et al. Pharmacological evidence that the activation of the $\mathrm{Na}+\mathrm{Ca} 2+$ exchanger protects $\mathrm{C} 6$ glioma cells during chemical hypoxia. Br J Pharmacol 1997; 121: 303-309.

34. Taglialatela M, Castaldo P, lossa S, Pannaccione A, Fresi A, Ficker E et al. Regulation of the human ether-a-gogo related gene (HERG) $\mathrm{K}+$ channels by reactive oxygen species. Proc Natl Acad Sci 1997; 94: 11698-11703.

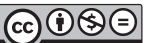

This work is licensed under a Creative Commons Attribution-NonCommercial-NoDerivs 4.0 International License. The images or other third party material in this article are included in the article's Creative Commons license, unless indicated otherwise in the credit line; if the material is not included under the Creative Commons license, users will need to obtain permission from the license holder to reproduce the material. To view a copy of this license, visit http://creativecommons.org/licenses/by-nc-nd/4.0/

(C) The Author(s) 2017 